Supporting Information

\title{
Improving the Kumada Catalyst Transfer Polymerization with Water-Scavenging Grignard Reagents
}

\author{
Susan Cheng ${ }^{\dagger}$, Shuyang Ye ${ }^{\dagger}$, Chirag N. Apte ${ }^{\dagger}$, Andrei K. Yudin ${ }^{\dagger}$, and Dwight S. Seferos ${ }^{\dagger *}$ \\ $\dagger$ Department of Chemistry, University of Toronto, 80 St. George Street, Toronto, Ontario, M5S 3H6, Canada \\ * Department of Chemical Engineering and Applied Chemistry, University of Toronto, 200 College Street, Toronto, \\ Ontario M5S 3E5, Canada \\ * Corresponding author: dwight.seferos@utoronto.ca
}


Contents

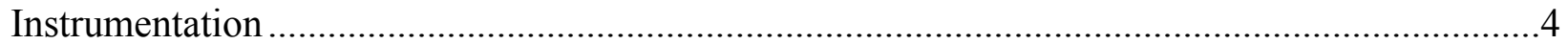

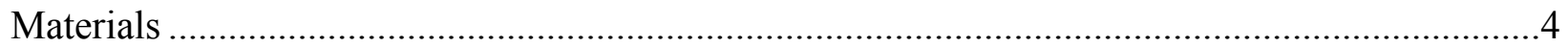

Scheme S1: Synthesis of PEGylated thiophene and fluorene monomers..................................5

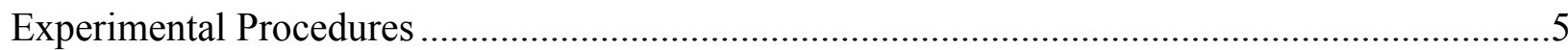

Figure S1: a) ${ }^{1} \mathrm{H}(500 \mathrm{MHz})$ and b) ${ }^{13} \mathrm{C}$ NMR (126 MHz) of octa(ethylene glycol) methyl ether

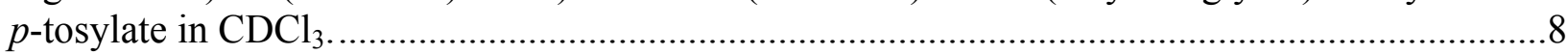

Figure S2: a) ${ }^{1} \mathrm{H}(500 \mathrm{MHz})$ and b) ${ }^{13} \mathrm{C}$ NMR (126 MHz) of 2-(2-bromothiophen-3-yl)ethanol in $\mathrm{CDCl}_{3}$

Figure S3: a) ${ }^{1} \mathrm{H}(500 \mathrm{MHz})$ and b) ${ }^{13} \mathrm{C}$ NMR (126 MHz) of 2-bromo-3-[nona(ethylene glycol) monomethyl ether]thiophene in $\mathrm{CDCl}_{3}$.

Figure S4: a) ${ }^{1} \mathrm{H}(500 \mathrm{MHz})$ and b) ${ }^{13} \mathrm{C}$ NMR $(126 \mathrm{MHz})$ of 2,5-dibromo-3-[nona(ethylene glycol) monomethyl ether] thiophene in $\mathrm{CDCl}_{3}$.

Figure S5: a) ${ }^{1} \mathrm{H}(500 \mathrm{MHz})$ and b) ${ }^{13} \mathrm{C}$ NMR $(126 \mathrm{MHz})$ of iodotri(ethylene glycol) monomethyl ether in $\mathrm{CDCl}_{3}$.

Figure S6: a) ${ }^{1} \mathrm{H}(500 \mathrm{MHz})$ and b) ${ }^{13} \mathrm{C}$ NMR (126 MHz) of 2-bromo-7-iodo-9,9-bis[tri(ethylene glycol) monomethyl ether]fluorene in $\mathrm{CDCl}_{3}$.

Figure S7: a) ${ }^{1} \mathrm{H}(500 \mathrm{MHz})$ and b) ${ }^{13} \mathrm{C}$ NMR $(126 \mathrm{MHz})$ of poly(M1) polymerized without $\mathrm{TIPMgBr}$, in $\mathrm{CDCl}_{3}$. From the integration ratio between the thiophene backbone protons and the $o$-tolyl methyl protons, the degree of polymerization is determined to be 23 repeat units. ...... 14

Figure S8: a) ${ }^{1} \mathrm{H}(500 \mathrm{MHz})$ and b) ${ }^{13} \mathrm{C}$ NMR (126 MHz) of poly(M1) polymerized with $1 \mathrm{eq}$. TIPMgBr, in $\mathrm{CDCl}_{3}$. From the integration ratio between the thiophene backbone protons and the $o$-tolyl methyl protons, the degree of polymerization is determined to be 22 repeat units.

Figure S9: a) ${ }^{1} \mathrm{H}(500 \mathrm{MHz})$ and b) ${ }^{13} \mathrm{C}$ NMR (126 MHz) of poly(M2) polymerized without $\mathrm{TIPMgBr}$, in $\mathrm{CDCl}_{3}$. From the integration ratio between the thiophene backbone protons and the $o$-tolyl methyl protons, the degree of polymerization is determined to be 14 repeat units. ..........16

Figure S10: a) ${ }^{1} \mathrm{H}(500 \mathrm{MHz})$ and b) ${ }^{13} \mathrm{C} \mathrm{NMR}(126 \mathrm{MHz})$ of poly(M2) polymerized with 1 eq. TIPMgBr, in $\mathrm{CDCl}_{3}$. From the integration ratio between the thiophene backbone protons and the $o$-tolyl methyl protons, the degree of polymerization is determined to be 17 repeat units.

Figure S11: a) ${ }^{1} \mathrm{H}(500 \mathrm{MHz})$ and b) ${ }^{13} \mathrm{C} \mathrm{NMR}(126 \mathrm{MHz})$ of poly(M3) polymerized without TIPMgBr, in $\mathrm{CDCl}_{3}$ (Table S2, Entry 2).

Figure S12: a) ${ }^{1} \mathrm{H}(500 \mathrm{MHz})$ and b) ${ }^{13} \mathrm{C} \mathrm{NMR}(126 \mathrm{MHz})$ of poly(M3) polymerized with 1 eq. $\mathrm{TIPMgBr}$, in $\mathrm{CDCl}_{3}$ (Table S2, Entry 1).

Figure S13: a) ${ }^{1} \mathrm{H}(500 \mathrm{MHz})$ and b) ${ }^{13} \mathrm{C}$ NMR $(126 \mathrm{MHz})$ of poly(M3) polymerized without TIPMgBr, in $\mathrm{CDCl}_{3}$ (Table S2, Entry 6).

Figure S14: a) ${ }^{1} \mathrm{H}(500 \mathrm{MHz})$ and b) ${ }^{13} \mathrm{C}$ NMR (126 MHz) of poly(M3) polymerized with 0.5 eq. TIPMgBr, in $\mathrm{CDCl}_{3}$ (Table S2, Entry 5).

Figure S15: a) ${ }^{1} \mathrm{H}(500 \mathrm{MHz})$ and b) ${ }^{13} \mathrm{C} \mathrm{NMR}(126 \mathrm{MHz})$ of poly(M3) polymerized with 0.5 eq. TIPMgBr, in $\mathrm{CDCl}_{3}$ (Table S2, Entry 3). 
Figure S16: ${ }^{1} \mathrm{H}$ NMR results of $\mathbf{M} 2$ Grignard metathesized with $i$-PrMgCl and quenched with water. The presence of TIPMgBr does not change the ratios of isomers (metathesis at the 2- vs. 5-position) observed after quenching. Error! Bookmark not defined.

Figure S17: GPC trace of poly(M1) polymerized without TIPMgBr (eluent: THF, $40{ }^{\circ} \mathrm{C}$ ) ........23

Figure S18: GPC trace of poly(M1) polymerized in the presence of 1 equivalent TIPMgBr

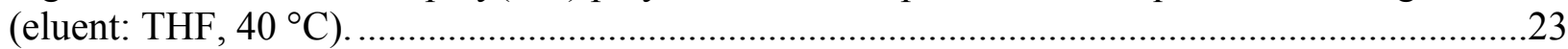

Figure S19: GPC trace of poly(M2) polymerized without TIPMgBr (eluent: THF, $40^{\circ} \mathrm{C}$ ) ........24

Figure S20: GPC trace of poly(M2) polymerized in the presence of 1 equivalent TIPMgBr (eluent: $\mathrm{THF}, 40{ }^{\circ} \mathrm{C}$ ).

Figure S21: GPC trace of poly(M3) polymerized in the presence of 1 equivalent $\mathrm{TIPMgBr}$ (eluent: THF, $40^{\circ} \mathrm{C}$ ). .25

Figure S22: GPC trace of poly(M3) polymerized without TIPMgBr (eluent: $\mathrm{THF}, 40{ }^{\circ} \mathrm{C}$ )........25

Calculation of expected DP based on polymerizable activated monomer ratio .25

Table S1: Summary of polythiophenes synthesized. .27

Table S2: Summary of polyfluorenes synthesized. .27

References: .28 
Instrumentation

NMR: ${ }^{1} \mathrm{H}$ NMR data for samples measured in $\mathrm{CDCl}_{3}$ are referenced to internal residual $\mathrm{CHCl}_{3}(\delta$ 7.26). ${ }^{13} \mathrm{C}$ NMR data for samples measured in $\mathrm{CDCl}_{3}$ are referenced to internal $\mathrm{CDCl}_{3}(\delta 77.16)$. Samples are measured on either a $500 \mathrm{MHz}$ Agilent DD2 or $400 \mathrm{MHz}$ Bruker Avance III spectrometer.

THF GPC: Size exclusion chromatography (SEC) analysis was carried out with a Tosoh EcoSEC instrument (model HLC-8320 version 2.01) equipped with two Tosoh TSKgel SuperHM-M columns and a dual-flow refractive-index detector. HPLC grade THF stabilized with $250 \mathrm{ppm}$ BHT and $2.5 \mathrm{~g} / \mathrm{L}$ tetrabutylammonium bromide was used as eluent at $40{ }^{\circ} \mathrm{C}$ with a flow rate of $0.6 \mathrm{~mL} / \mathrm{min}$. Calibration curves for SEC analysis were obtained with polystyrene standards. Data processing was performed using the EcoSEC Data Analysis software (version 1.14).

Karl Fischer Titration: Water content for reagent-grade THF was determined by calorimetric titration on a Mettler Toledo C20 Karl Fischer coulometer.

Materials

3-(2-Hydroxyethyl)thiophene, tri(ethylene glycol) monomethyl ether, tetra(ethylene glycol) monomethyl ether, tetra(ethylene glycol) di( $p$-toluenesulfonate), 2-bromo-7-iodofluorene, 1,3bis(diphenylphosphino)propane (dppp), imidazole, iodine, isopropylmagnesium chloride ( $i$ $\operatorname{PrMgCl}$ ), isopropylmagnesium chloride lithium chloride complex (i-PrMgCl.LiCl), $N$ bromosuccinimide, nickel (II) acetylacetonate $\left(\mathrm{Ni}(\mathrm{acac})_{2}\right)$, potassium hydride, sodium hydride, 2,4,6-triisopropylphenylmagnesium bromide ( $\mathrm{TIPMgBr}$ ), and triphenylphosphine were purchased from Sigma and used without further purification.

Nickel (II) (o-tolyl)(1,2-bis(diphenylphosphino)ethane)chloride (Ni(o-tol)(dppe)Cl) was synthesized according to previously reported procedures. ${ }^{1}$ 
Scheme S1: Synthesis of PEGylated thiophene and fluorene monomers.
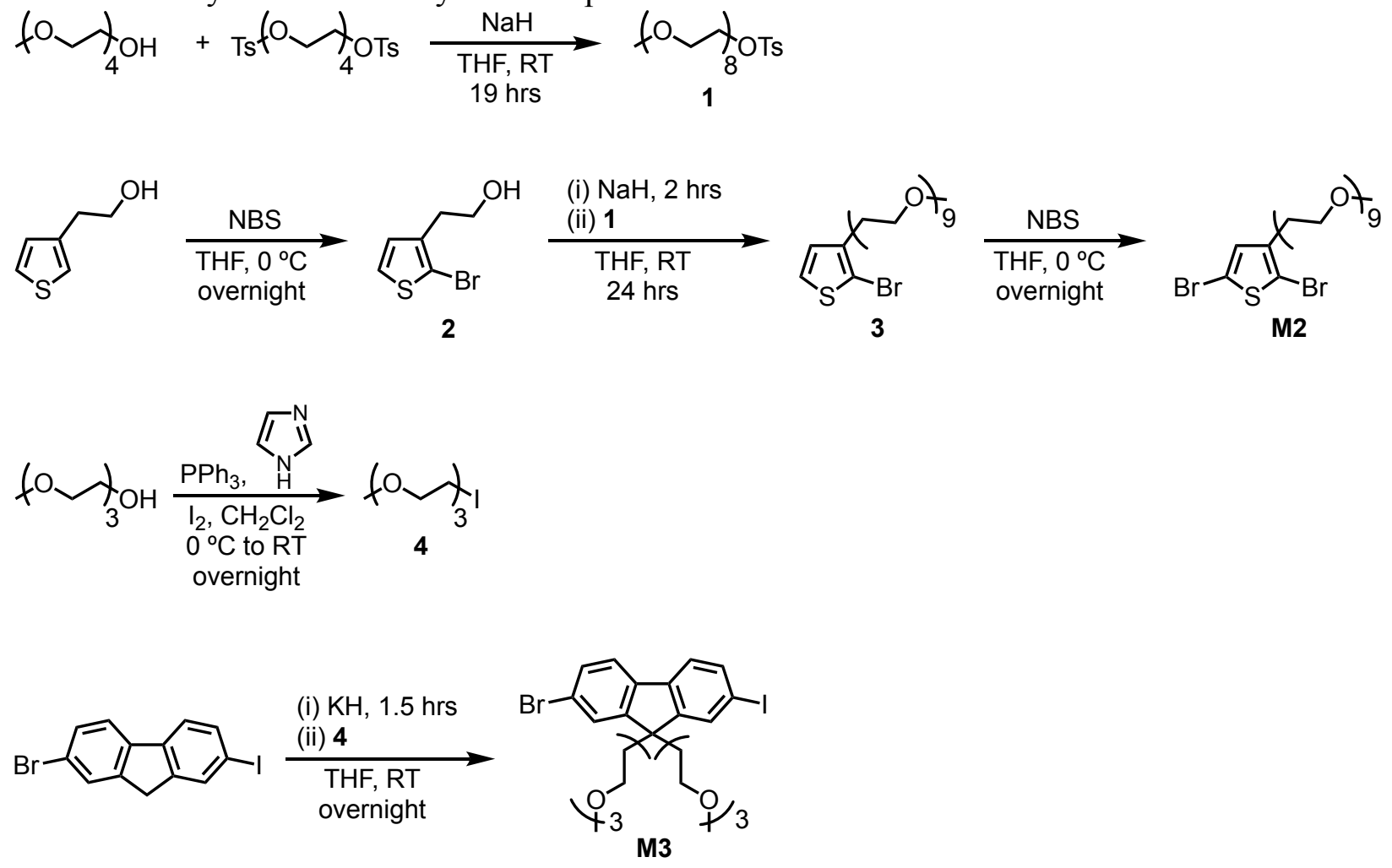

Experimental Procedures

Octa(ethylene glycol) methyl ether $p$-tosylate (1):

All glass apparatus was dried before use and the reaction was carried out under inert atmosphere. Sodium hydride $(0.35 \mathrm{~g}, 14.6 \mathrm{mmol})$ was added to a Schlenk flask and suspended in THF (15 $\mathrm{mL})$. A solution of tetra(ethylene glycol) monomethyl ether $(2.77 \mathrm{~g}, 13.3 \mathrm{mmol})$ in dry, degassed THF (15 mL) was added to the suspension via syringe over 5 minutes, then stirred for an additional 2 hours. The resulting solution was transferred via syringe over 10 minutes to a second Schlenk flask containing tetra(ethylene glycol) di( $p$-toluenesulfonate) (10 g, $19.9 \mathrm{mmol})$ in THF $(48 \mathrm{~mL})$. The solution was stirred overnight (19 hours) at room temperature before solvent was removed in vасио. The dry residue was redissolved in dichloromethane, washed with saturated brine solution, and dried over sodium sulfate. Purification was carried out by silica gel column chromatography with 20:80 acetone/chloroform to elute unreacted tetra(ethylene glycol) $\operatorname{di}(p$ toluenesulfonate), followed by increasing solvent polarity to 35:65 acetone/chloroform to elute the desired product $(3.26 \mathrm{~g}, 45.5 \%)$ as a pale yellow oil. ${ }^{1} \mathrm{H} \mathrm{NMR}\left(500 \mathrm{MHz}, \mathrm{CDCl}_{3}\right) \delta 7.84-$ $7.78(\mathrm{~m}, 2 \mathrm{H}), 7.36-7.32(\mathrm{~m}, 2 \mathrm{H}), 4.16(\mathrm{ddd}, J=5.9,3.9,1.0 \mathrm{~Hz}, 2 \mathrm{H}), 3.70-3.60(\mathrm{~m}, 24 \mathrm{H})$, $3.58(\mathrm{~d}, J=0.9 \mathrm{~Hz}, 4 \mathrm{H}), 3.56-3.52(\mathrm{~m}, 2 \mathrm{H}), 3.38(\mathrm{~s}, 3 \mathrm{H}), 2.45(\mathrm{~s}, 3 \mathrm{H}) .{ }^{13} \mathrm{C} \mathrm{NMR}(126 \mathrm{MHz}$, $\left.\mathrm{CDCl}_{3}\right) \delta 144.9,133.2,123.0,128.1,72.1,70.9,70.8-70.6(\mathrm{~m}), 69.4,68.9,59.2,21.8$.

2-(2-Bromothiophen-3-yl)ethanol (2):

A reaction flask containing a solution of 3-(2-Hydroxyethyl)thiophene (10 g, $78 \mathrm{mmol})$ in THF $(100 \mathrm{~mL})$ was cooled to $0^{\circ} \mathrm{C}$ in an ice bath. In a separate flask, $N$-Bromosuccinimide $(13.88 \mathrm{~g}, 78$ mmol) was suspended in THF (60 mL) and transferred via cannula to the 3-(2- 
hydroxyethyl)thiophene solution. The reaction mixture was protected from light and allowed to gradually warm to room temperature while stirring overnight. The reaction mixture was then extracted with three portions of chloroform. The combined organic layers were washed with saturated sodium bicarbonate solution and dried over magnesium sulfate. Silica gel column chromatography with dichloromethane as the eluent was used to purify the product $(7.88 \mathrm{~g}$, $48.8 \%)$, obtained as a yellow oil. ${ }^{1} \mathrm{H} \mathrm{NMR}\left(500 \mathrm{MHz}, \mathrm{CDCl}_{3}\right) \delta 7.23(\mathrm{~d}, J=5.6 \mathrm{~Hz}, 1 \mathrm{H}), 6.87$ $(\mathrm{d}, J=5.6 \mathrm{~Hz}, 1 \mathrm{H}), 3.84(\mathrm{td}, J=6.6,0.7 \mathrm{~Hz}, 2 \mathrm{H}), 2.86(\mathrm{t}, J=6.6 \mathrm{~Hz}, 2 \mathrm{H}), 1.58-1.53(\mathrm{br}, 1 \mathrm{H})$. ${ }^{13} \mathrm{C} \mathrm{NMR}\left(126 \mathrm{MHz}, \mathrm{CDCl}_{3}\right) \delta 138.1,128.7,125.9,110.5,62.2,32.9$.

2-Bromo-3-[nona(ethylene glycol) monomethyl ether]thiophene (3):

All glass apparatus was dried before use and the reaction was carried out under inert atmosphere. $2(0.500 \mathrm{~g}, 2.41 \mathrm{mmol})$ was added via syringe to a Schlenk flask containing a suspension of sodium hydride $(0.174 \mathrm{~g}, 7.24 \mathrm{mmol})$ in THF $(2 \mathrm{~mL})$ and stirred for 2 hours. A solution of 1 $(1.236 \mathrm{~g}, 2.29 \mathrm{mmol})$ in THF $(8 \mathrm{~mL})$ was added via syringe and left to stir for 24 hours at room temperature. The reaction was quenched with $1 \mathrm{~mL}$ water and solvent was removed in vacuo. The dried residue was dispersed in dichloromethane to form a cloudy mixture, then centrifuged to separate the insoluble powder from the dichloromethane solution containing the product. The supernatant was decanted and the pellet was extracted twice more with dichloromethane followed by centrifugation. The dichloromethane extracts were combined and purified by reverse phase column chromatography (C18-functionalized silica gel) with gradient elution starting with 20:80 acetonitrile/water and decreasing in polarity until 70:30 acetonitrile/water. The desired product $(0.825 \mathrm{~g}, 62.8 \%)$ was obtained as a clear, colourless oil. ${ }^{1} \mathrm{H} \mathrm{NMR}\left(500 \mathrm{MHz}, \mathrm{CDCl}_{3}\right) \delta$ $7.19(\mathrm{~d}, J=5.6 \mathrm{~Hz}, 1 \mathrm{H}), 6.88(\mathrm{~d}, J=5.6 \mathrm{~Hz}, 1 \mathrm{H}), 3.67-3.60(\mathrm{~m}, 32 \mathrm{H}), 3.56-3.53(\mathrm{~m}, 2 \mathrm{H})$, $3.38(\mathrm{~s}, 3 \mathrm{H}), 2.87(\mathrm{t}, J=7.0 \mathrm{~Hz}, 2 \mathrm{H}) .{ }^{13} \mathrm{C} \mathrm{NMR}\left(126 \mathrm{MHz}, \mathrm{CDCl}_{3}\right) \delta 138.5,128.8,125.5,110.0$, $72.1,70.9-70.6(\mathrm{~m}), 70.4(\mathrm{~d}, J=5.8 \mathrm{~Hz}), 59.2,30.1$.

2,5-Dibromo-3-[nona(ethylene glycol) monomethyl ether]thiophene (M2):

$3(0.600 \mathrm{~g}, 1.05 \mathrm{mmol})$ was weighed into a vial, dissolved in THF $(5 \mathrm{~mL})$ and cooled to $0^{\circ} \mathrm{C}$ in an ice bath. $N$-Bromosuccinimide was added slowly to the vial and the resulting solution was protected from light and allowed to slowly warm up to room temperature while stirring overnight. The reaction mixture was then poured into a saturated sodium bicarbonate solution, extracted three times with chloroform, and washed three times with saturated brine. The product $(0.663 \mathrm{~g}, 97.2 \%)$ was dried in vacuo. ${ }^{1} \mathrm{H} \mathrm{NMR}\left(500 \mathrm{MHz}, \mathrm{CDCl}_{3}\right) \delta 6.89(\mathrm{~s}, 1 \mathrm{H}), 3.66-3.60(\mathrm{~m}$, $32 \mathrm{H}), 3.56-3.53(\mathrm{~m}, 2 \mathrm{H}), 3.37(\mathrm{~s}, 3 \mathrm{H}), 2.80(\mathrm{t}, J=6.8 \mathrm{~Hz}, 2 \mathrm{H}) .{ }^{13} \mathrm{C} \mathrm{NMR}\left(126 \mathrm{MHz}, \mathrm{CDCl}_{3}\right) \delta$ 139.7, 131.6, $109.8(\mathrm{~d}, J=176.9 \mathrm{~Hz}), 73.6-67.1(\mathrm{~m}), 59.2,30.1$.

Iodotri(ethylene glycol) monomethyl ether (4):

An Erlenmeyer flask containing triphenylphosphine $(15.97 \mathrm{~g}, 60.9 \mathrm{mmol})$ and imidazole $(4.15 \mathrm{~g}$, $60.9 \mathrm{mmol})$ dissolved in dichloromethane $(100 \mathrm{~mL})$ was cooled to $0^{\circ} \mathrm{C}$ in an ice bath. Iodine in dichloromethane $(25 \mathrm{~mL})$ was added to the flask, resulting in a dark orange solution. A solution of tri(ethylene glycol) monomethyl ether $(5 \mathrm{~g}, 30.5 \mathrm{mmol})$ in dichloromethane $(25 \mathrm{~mL})$ was added dropwise to the flask, and the reaction mixture was allowed to warm up to room temperature while stirring overnight. The reaction mixture was then poured into water, extracted three times with dichloromethane, and washed with saturated brine solution. Silica gel column chromatography with 1:1 hexanes/ethyl acetate as the eluent was used to purify the product $(6.57,74.4 \%) .{ }^{1} \mathrm{H} \mathrm{NMR}\left(400 \mathrm{MHz}, \mathrm{CDCl}_{3}\right) \delta 3.78-3.73(\mathrm{~m}, 2 \mathrm{H}), 3.70-3.63(\mathrm{~m}, 6 \mathrm{H}), 3.58-$ 
$3.53(\mathrm{~m}, 2 \mathrm{H}), 3.38(\mathrm{~d}, \mathrm{~J}=0.7 \mathrm{~Hz}, 3 \mathrm{H}), 3.26(\mathrm{ddd}, \mathrm{J}=7.4,6.5,0.7 \mathrm{~Hz}, 2 \mathrm{H}) .{ }^{13} \mathrm{C} \mathrm{NMR}(126 \mathrm{MHz}$, $\left.\mathrm{CDCl}_{3}\right) \delta 72.1(\mathrm{~d}, \mathrm{~J}=5.4 \mathrm{~Hz}), 70.7,70.3,59.2,3.0$.

2-Bromo-7-iodo-9,9-bis[tri(ethylene glycol) monomethyl ether]fluorene (M3):

All glass apparatus was dried before use and the reaction was carried out under inert atmosphere. 2-Bromo-7-iodofluorene $(3.25 \mathrm{~g}, 8.76 \mathrm{mmol})$ and potassium hydride $(1.62 \mathrm{~g}, 20.2 \mathrm{mmol})$ were weighed into a Schlenk flask and dissolved in THF $(100 \mathrm{~mL})$. The solution was stirred for 1.5 hours, during which gas evolution was evident and the colour changed from bright orange to red. $4(6.00 \mathrm{~g}, 21.9 \mathrm{mmol})$ was diluted with THF $(24 \mathrm{~mL})$ and added dropwise to the reaction flask, accompanied by a reaction colour change from red to pink. The reaction mixture was stirred overnight at room temperature. The reaction mixture was then poured into water, extracted with three portions of dichloromethane, and washed with saturated brine solution. Silica gel column chromatography with ethyl acetate as the eluent was used to purify the product $(0.869 \mathrm{~g}, 15.0 \%)$. ${ }^{1} \mathrm{H}$ NMR $\left(500 \mathrm{MHz}, \mathrm{CDCl}_{3}\right) \delta 7.73(\mathrm{~d}, \mathrm{~J}=1.5 \mathrm{~Hz}, 1 \mathrm{H}), 7.66(\mathrm{ddd}, \mathrm{J}=7.9,1.5,0.6 \mathrm{~Hz}, 1 \mathrm{H}), 7.52$ $(\mathrm{d}, \mathrm{J}=1.6 \mathrm{~Hz}, 1 \mathrm{H}), 7.51(\mathrm{~d}, \mathrm{~J}=8.1 \mathrm{~Hz}, 1 \mathrm{H}), 7.46(\mathrm{ddd}, \mathrm{J}=8.1,1.7,0.6 \mathrm{~Hz}, 1 \mathrm{H}), 7.39(\mathrm{~d}, \mathrm{~J}=8.0$ $\mathrm{Hz}, 1 \mathrm{H}), 3.55-3.46(\mathrm{~m}, 8 \mathrm{H}), 3.41-3.36(\mathrm{~m}, 4 \mathrm{H}), 3.34(\mathrm{~s}, 6 \mathrm{H}), 3.23-3.18(\mathrm{~m}, 4 \mathrm{H}), 2.77$ (dd, J $=7.9,6.9 \mathrm{~Hz}, 4 \mathrm{H}), 2.32(\mathrm{t}, \mathrm{J}=7.4 \mathrm{~Hz}, 4 \mathrm{H}) .{ }^{13} \mathrm{C} \mathrm{NMR}\left(126 \mathrm{MHz}, \mathrm{CDCl}_{3}\right) \delta 151.0(\mathrm{~d}, J=42.1$ $\mathrm{Hz}), 138.9(\mathrm{~d}, J=70.0 \mathrm{~Hz}), 136.7,132.7,130.8,126.8,122.4-120.9(\mathrm{~m}), 93.2,72.0,71.2-$ $69.5(\mathrm{~m}), 66.9,59.2,51.9,39.6$.

General polymerization procedure for thiophene monomers (M1 and M2):

All glass apparatus was dried before use and the reaction was carried out under inert atmosphere. The monomer was weighed into a reaction flask. TIPMgBr (1 equivalent) or an equal volume of THF was added and the resulting solution was stirred for 10 minutes. $i$ - $\mathrm{PrMgCl}(0.98$ equivalents) was added to the monomer solution and Grignard metathesis was allowed to proceed for 10 minutes. The polymerization was initiated by injection of $\mathrm{Ni}(o$-tol $)(\mathrm{dppe}) \mathrm{Cl}(3$ mol\%) in THF. After 5 minutes, the polymerization was quenched with acidified methanol.

General polymerization procedure for fluorene monomers (M3):

All glass apparatus was dried before use and the reaction was carried out under inert atmosphere. The monomer was weighed into a reaction flask. TIPMgBr ( 0.5 to 1 equivalents $)$ or an equal volume of THF was added and the resulting solution was stirred for 10 minutes. $i$-PrMgCl.LiCl ( 0.98 equivalents) was added to the monomer solution and Grignard metathesis was allowed to proceed for 30 minutes. $\mathrm{Ni}(\mathrm{acac})_{2}$ and dppp in a 1 to 1.03 mole ratio (relative to each other) were dissolved in THF and stirred for 30 minutes in a separate flask to generate the $\mathrm{Ni}(\mathrm{acac})_{2} / \mathrm{dppp}$ catalyst. The catalyst solution ( $5 \mathrm{~mol} \%$ relative to the monomer) was injected into the activated monomer solution to initiate the polymerization. After 1 hour, the polymerization was quenched with acidified methanol. 
a) Octa(ethylene glycol) methyl ether $p$-tosylate (1)

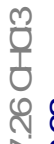

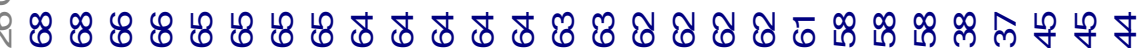

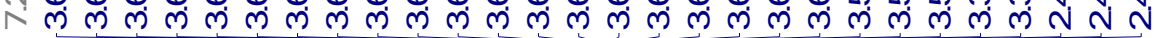

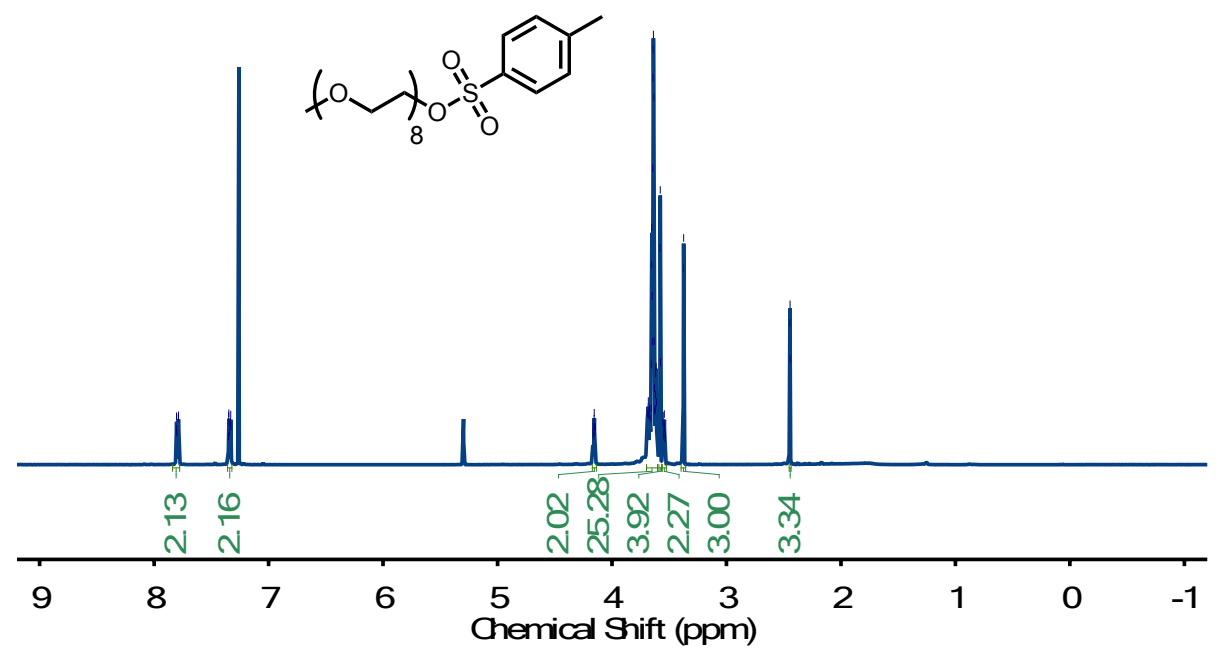

b) Octa(ethylene glycol) methyl ether prtosylate (1)
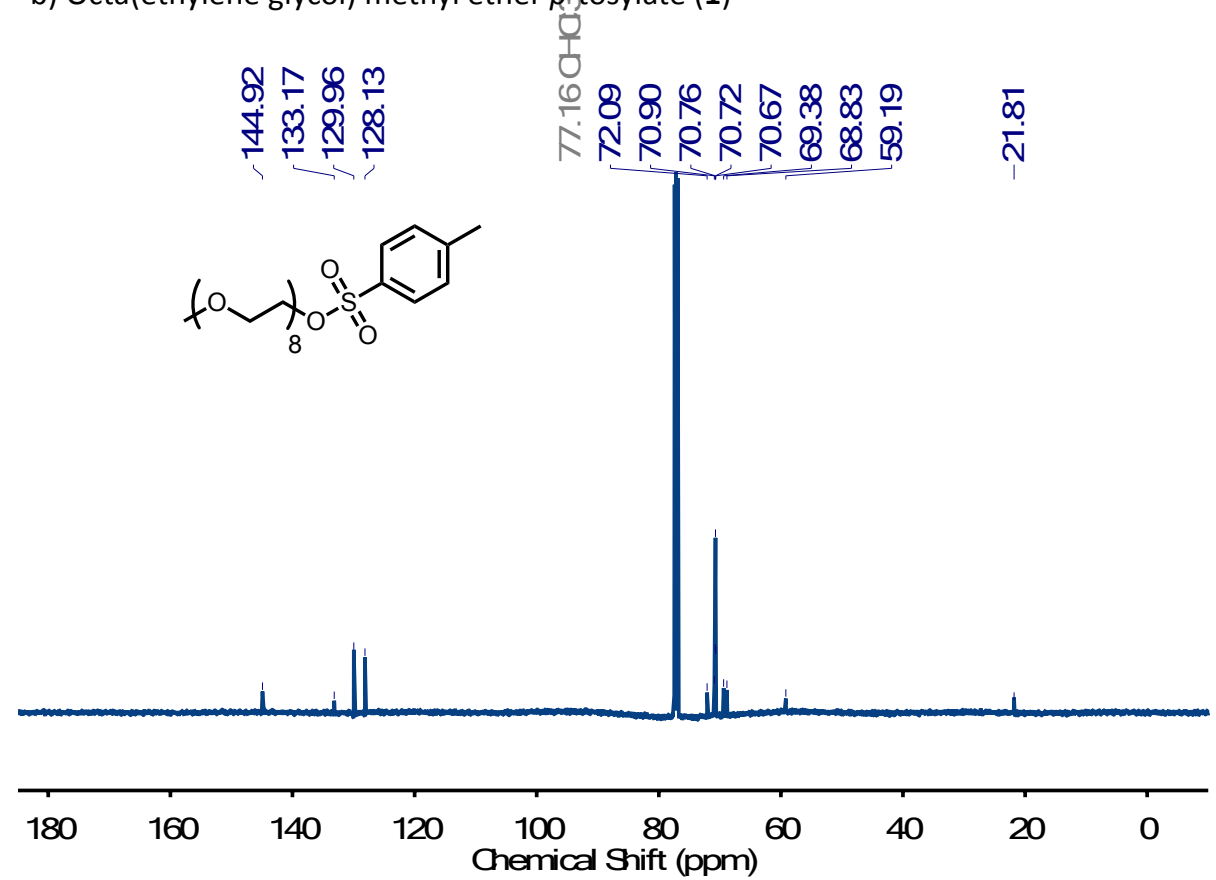

Figure S1: a) ${ }^{1} \mathrm{H}(500 \mathrm{MHz})$ and b) ${ }^{13} \mathrm{C}$ NMR $(126 \mathrm{MHz})$ of octa(ethylene glycol) methyl ether $p$-tosylate in $\mathrm{CDCl}_{3}$. 
a) 2-(2-bromothiophen-3-yl)ethanol (2)

象

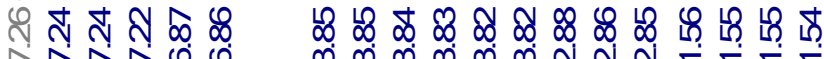

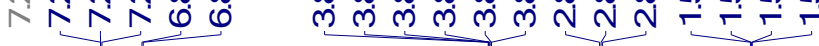

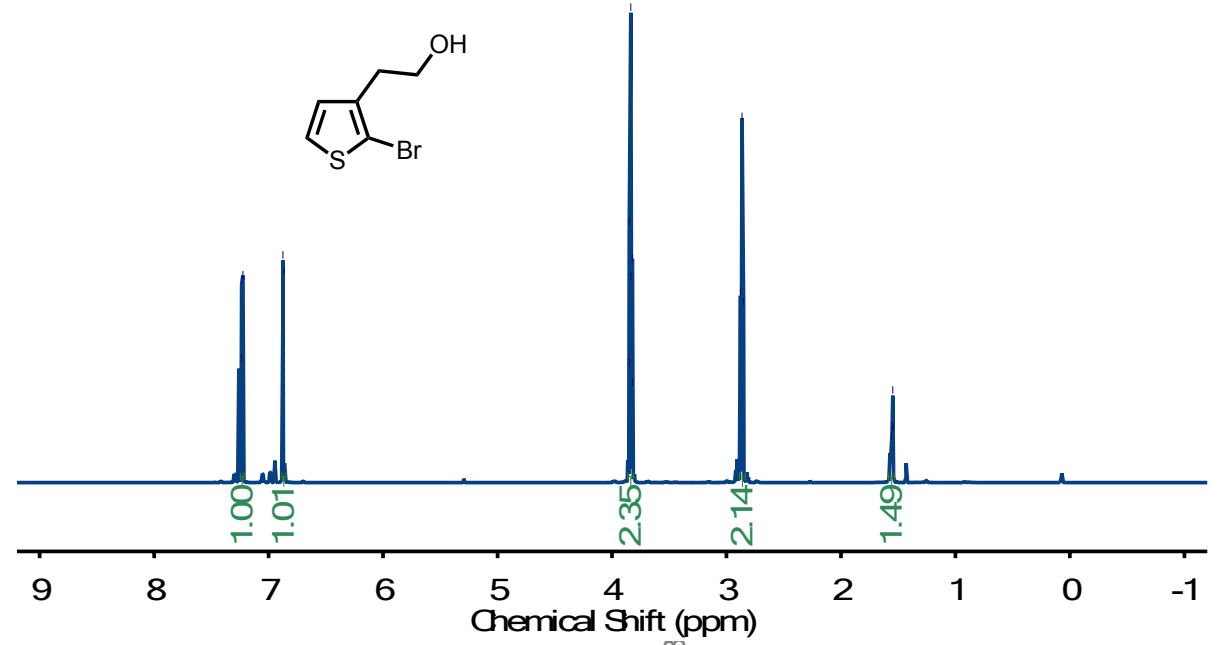

b) 2-(2-bromothiophen-3-yl)ethanol (2)

$\varnothing \hat{0} \otimes$

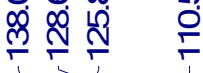

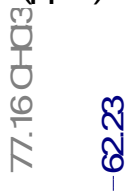

సे
ले
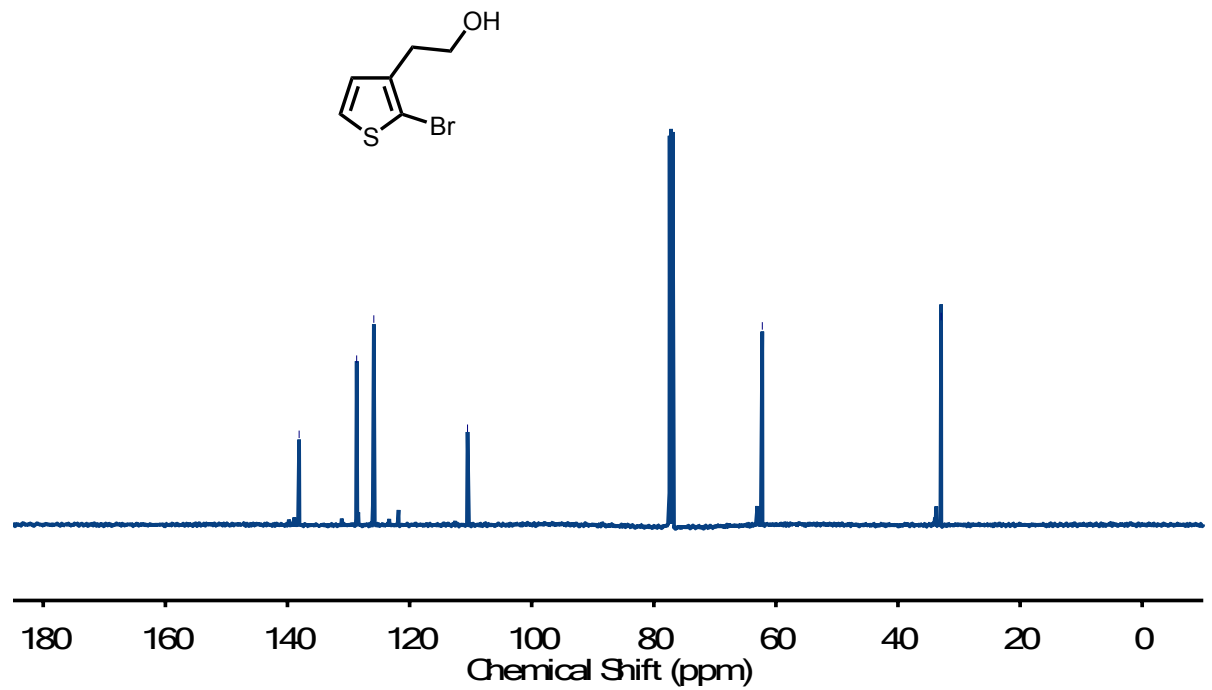

Figure S2: a) ${ }^{1} \mathrm{H}(500 \mathrm{MHz})$ and b) ${ }^{13} \mathrm{C}$ NMR (126 MHz) of 2-(2-bromothiophen-3-yl)ethanol in $\mathrm{CDCl}_{3}$. 
a) 2-bromo-3-[nona(ethylene glycol) monom \&thyl ether]thiophene (3)

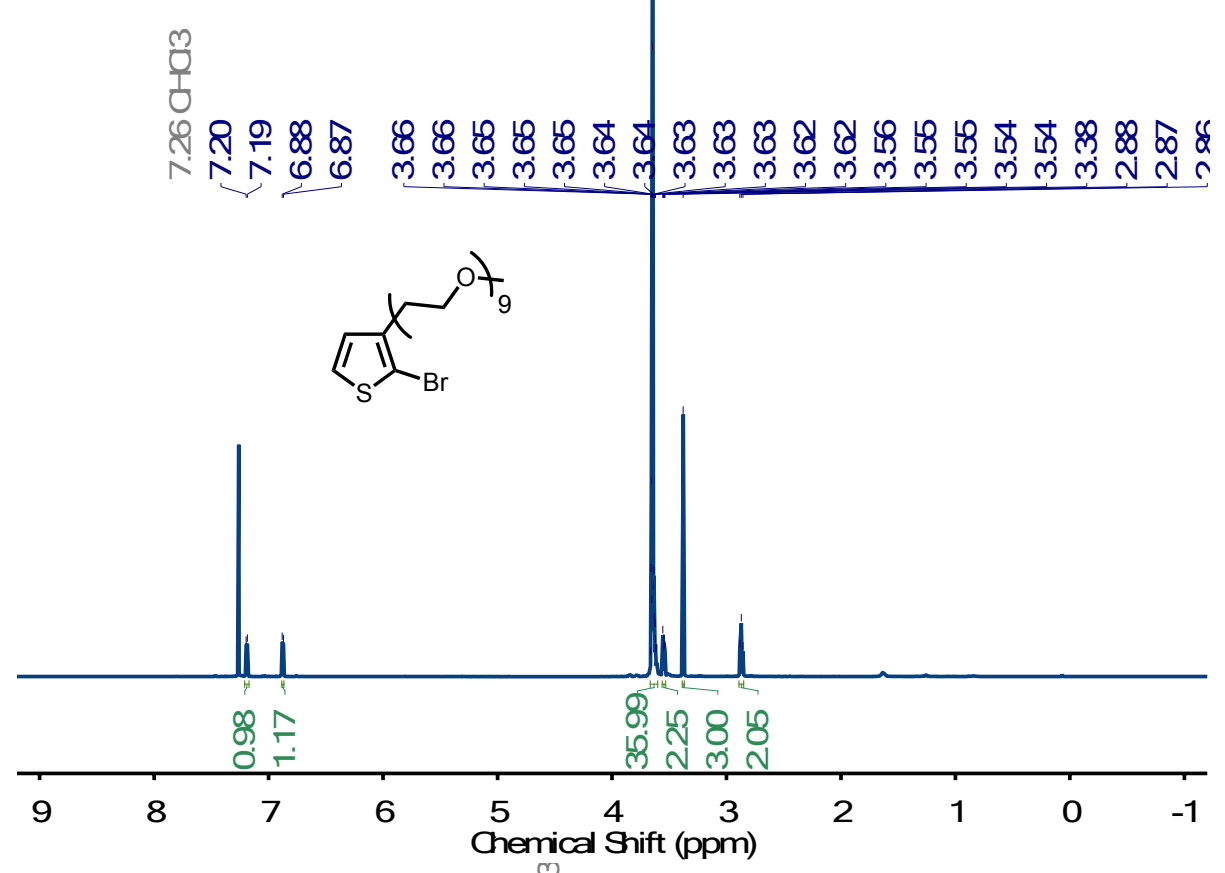

b) 2-bromo-3-[nona(ethylene glycol) monomethyl ether]thiophene (3)

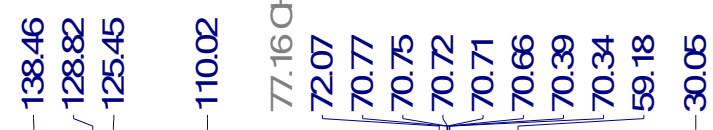

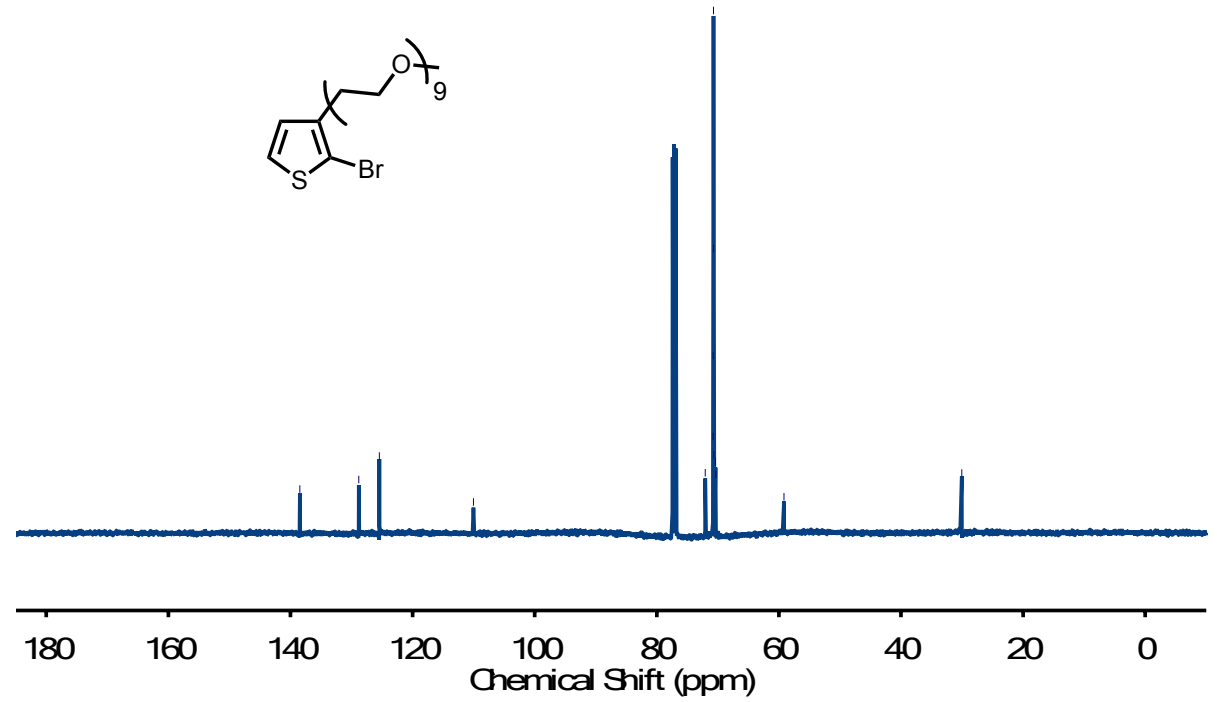

Figure S3: a) ${ }^{1} \mathrm{H}(500 \mathrm{MHz})$ and b) ${ }^{13} \mathrm{C} \mathrm{NMR}(126 \mathrm{MHz})$ of 2-bromo-3-[nona(ethylene glycol) monomethyl ether]thiophene in $\mathrm{CDCl}_{3}$. 
a) 2,5-dibromo-3-[nona(ethylene glycol) monomethyl ether]thiophene (M2)

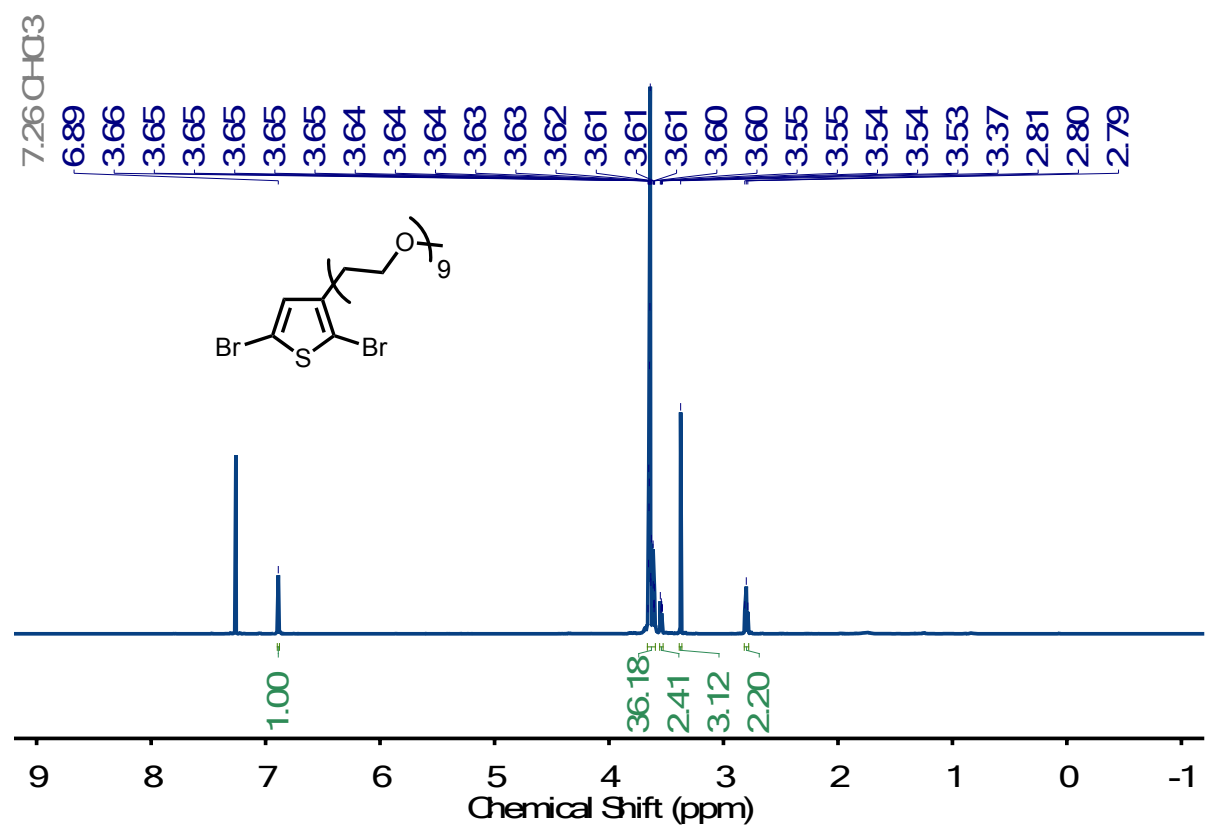

b) 2,5-dibromo-3-[nona(ethylene glycol) monomethyl ether]thiophene (M2)
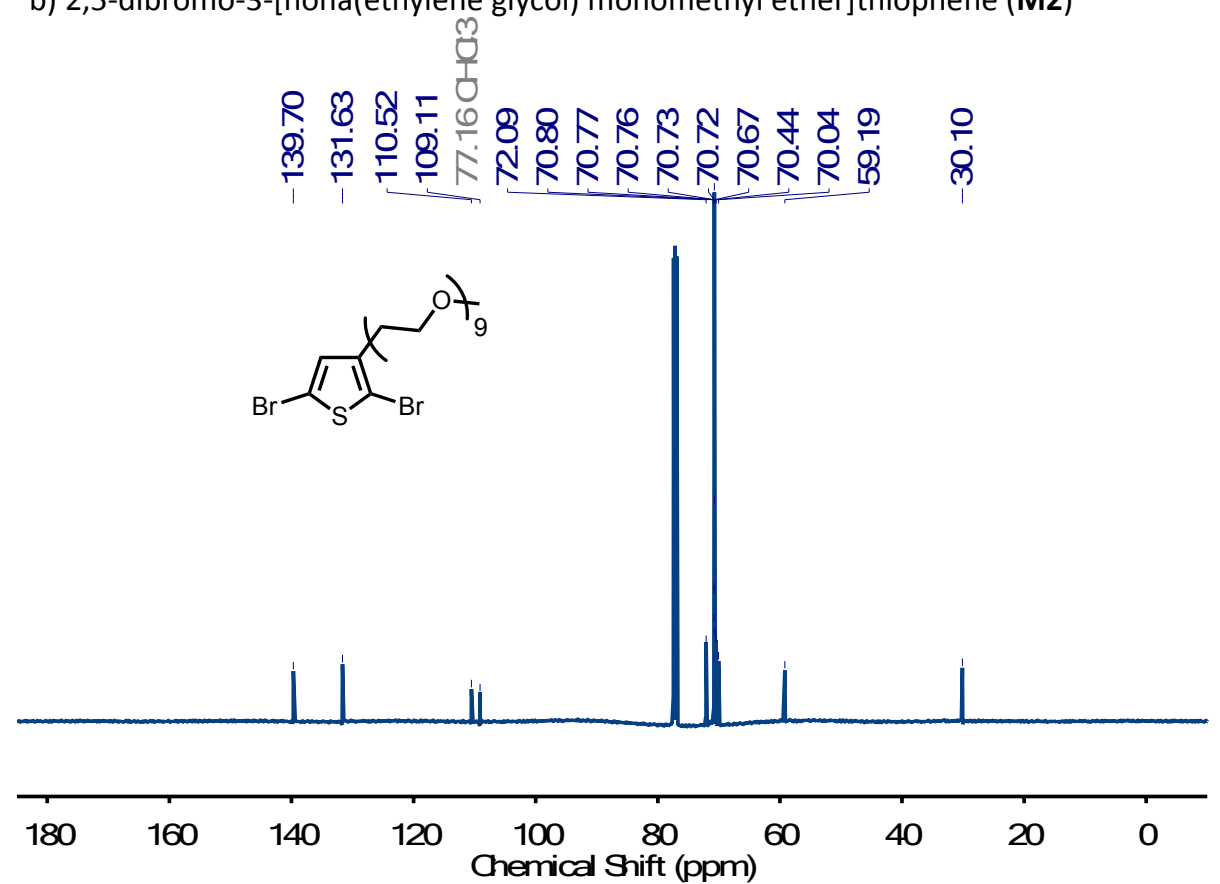

Figure S4: a) ${ }^{1} \mathrm{H}(500 \mathrm{MHz})$ and b) ${ }^{13} \mathrm{C}$ NMR (126 MHz) of 2,5-dibromo-3-[nona(ethylene glycol) monomethyl ether] thiophene in $\mathrm{CDCl}_{3}$. 
a) lodotri(ethylene glycol) monomethyl ether (4)
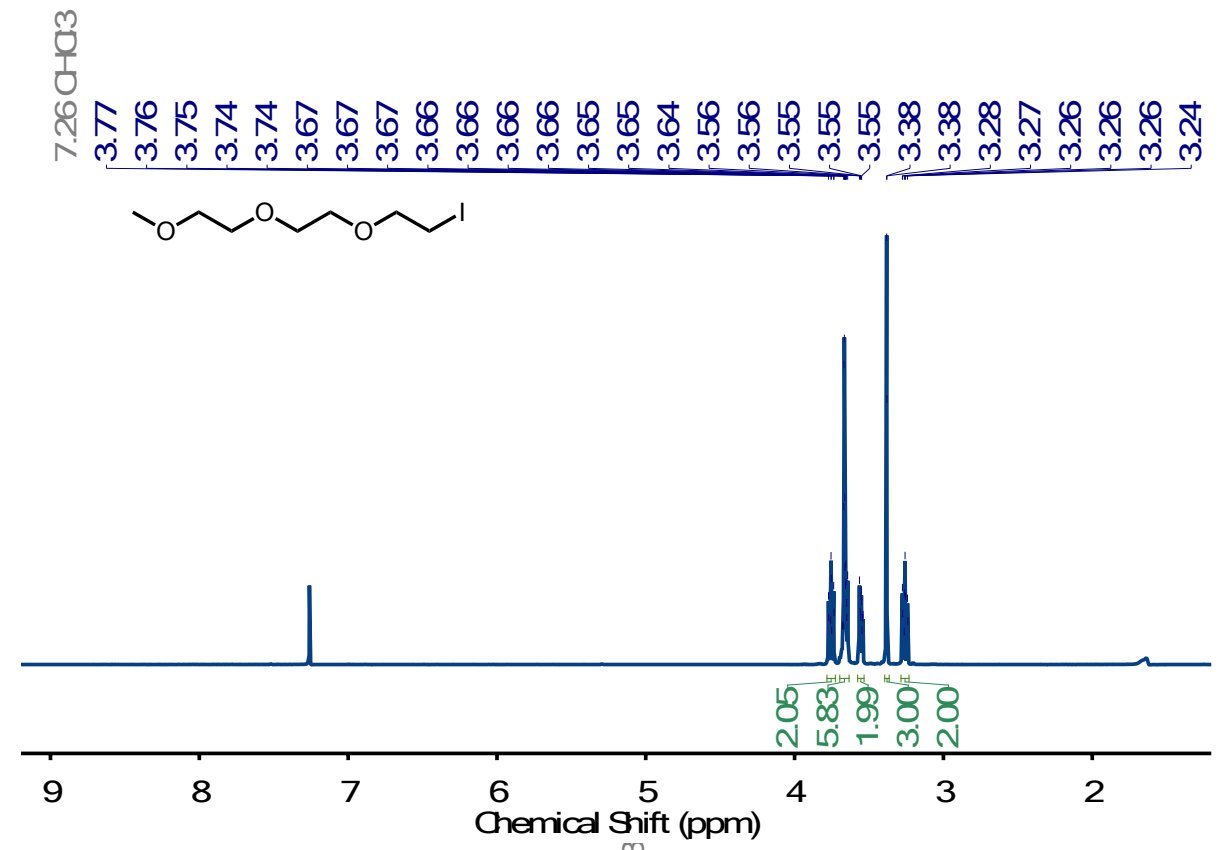

b) lodotri(ethylene glycol) monomethyl ethểr (4)

O

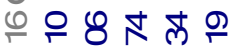

तN N<smiles>COCCOCCOCCI</smiles>

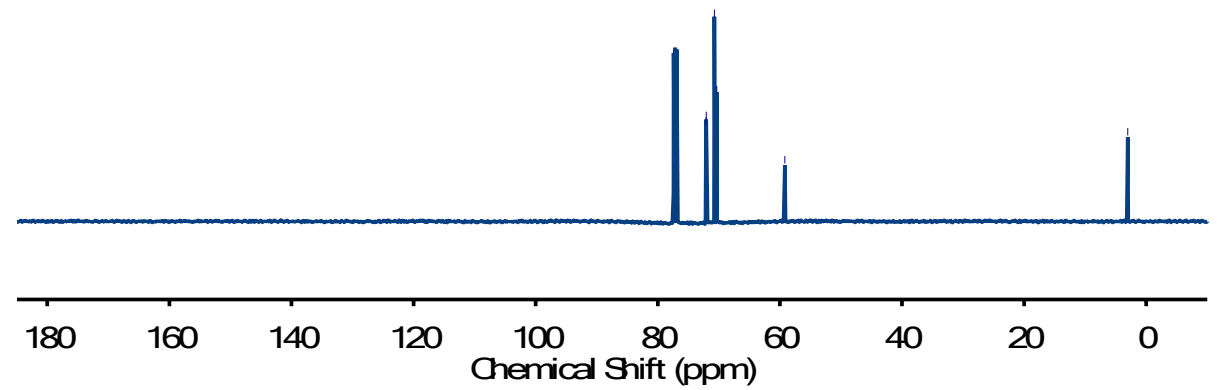

Figure S5: a) ${ }^{1} \mathrm{H}(500 \mathrm{MHz})$ and b) ${ }^{13} \mathrm{C}$ NMR $(126 \mathrm{MHz})$ of iodotri(ethylene glycol) monomethyl ether in $\mathrm{CDCl}_{3}$. 
a)2-bromo-7-iodo-9,9-bis[tri(ethylene glycol) monomethyl ether]fluorene (M3)

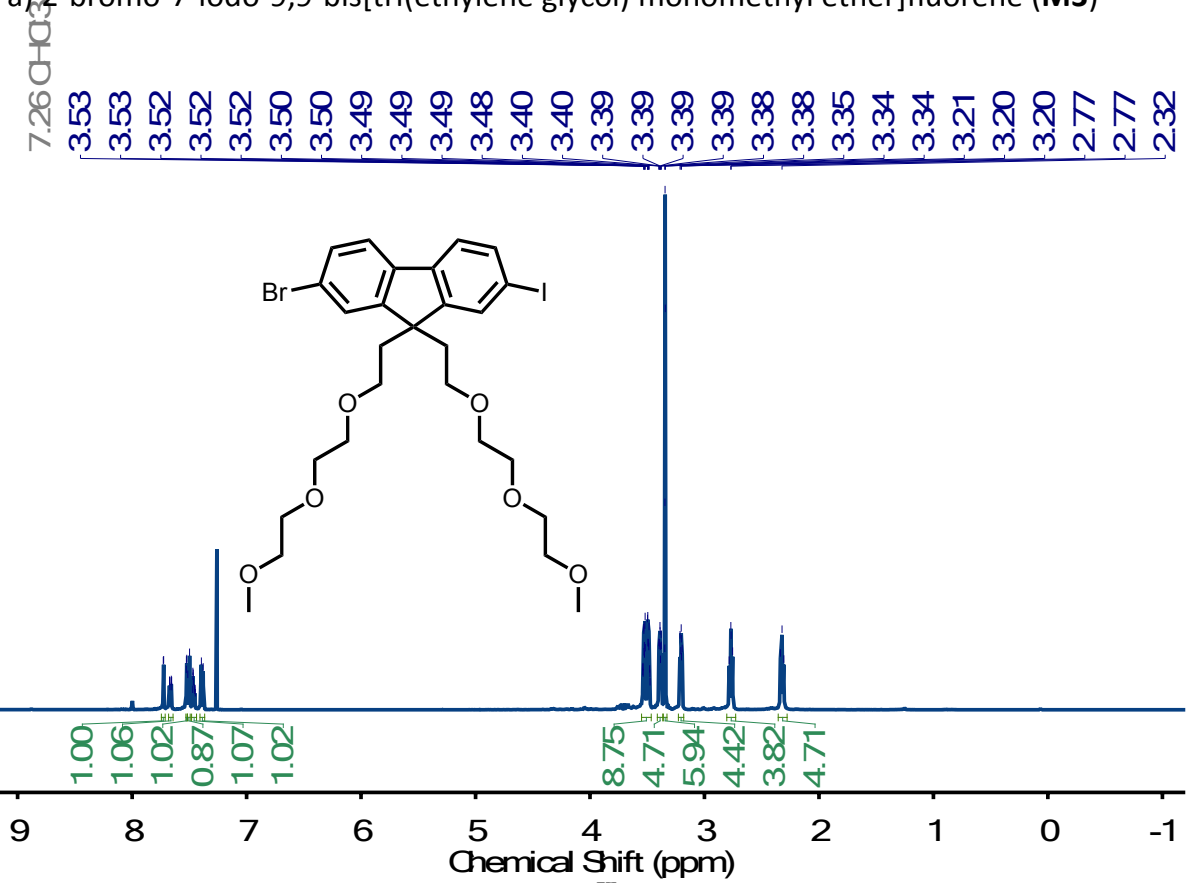

b) 2-bromo-7-iodo-9,9-bis[tri(ethylene glycôl) monomethyl ether]fluorene (M3)

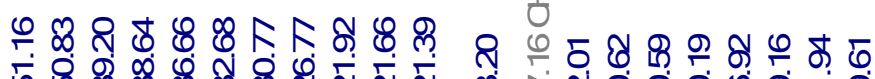

ர

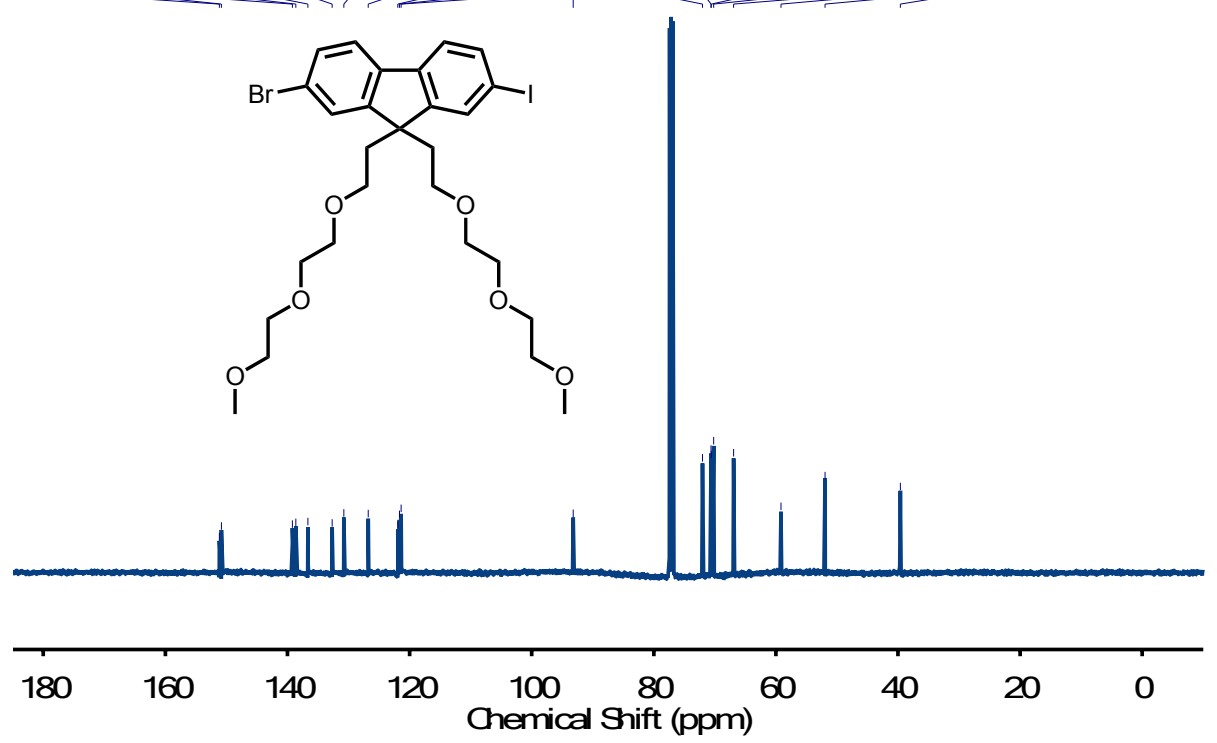

Figure S6: a) ${ }^{1} \mathrm{H}(500 \mathrm{MHz})$ and b) ${ }^{13} \mathrm{C}$ NMR (126 MHz) of 2-bromo-7-iodo-9,9-bis[tri(ethylene glycol) monomethyl ether]fluorene in $\mathrm{CDCl}_{3}$. 
a) poly(M1) polymerized without TIPMgBr

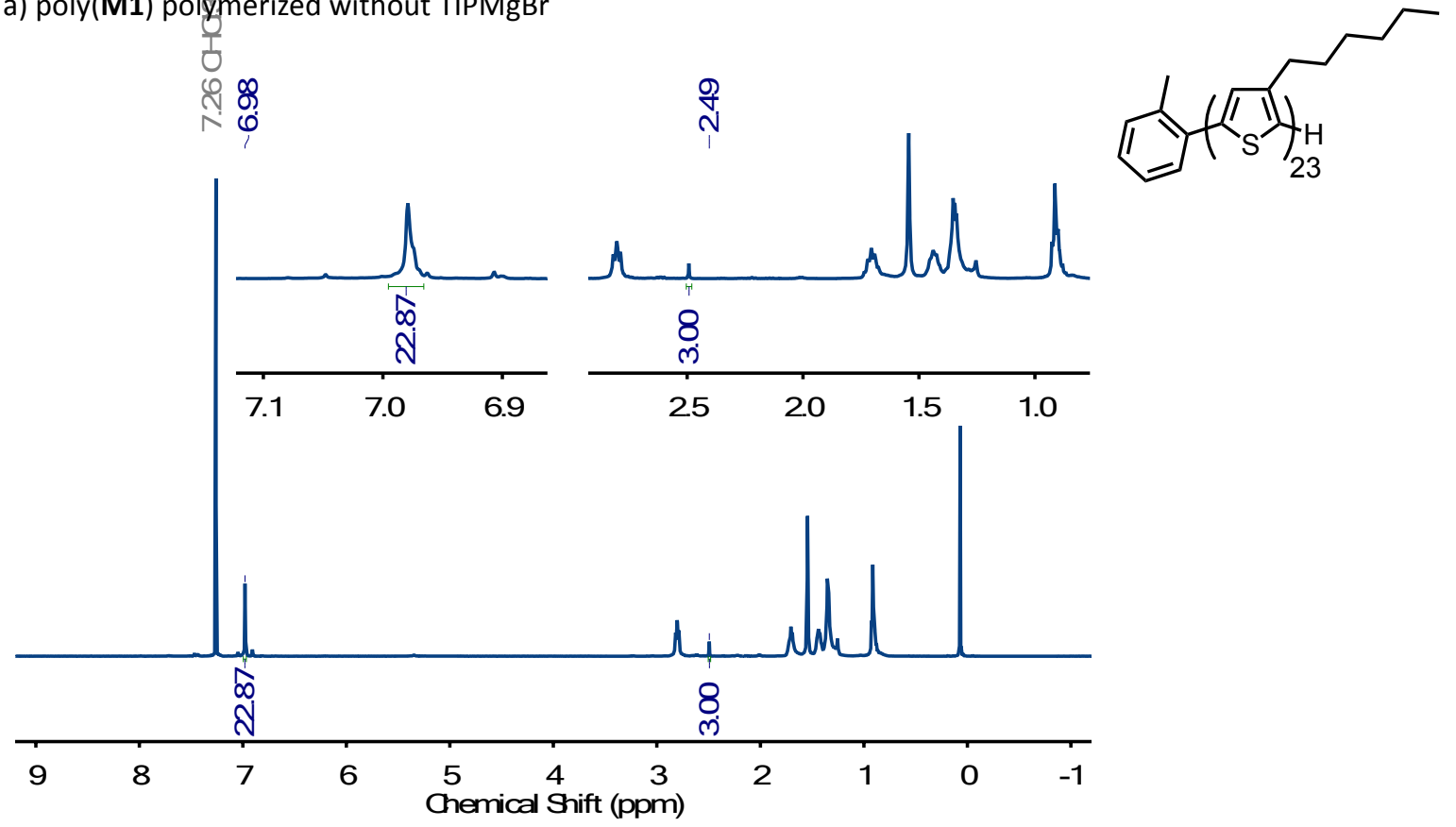

b) poly(M1) polymerized without $\mathrm{TIPMgBr}$
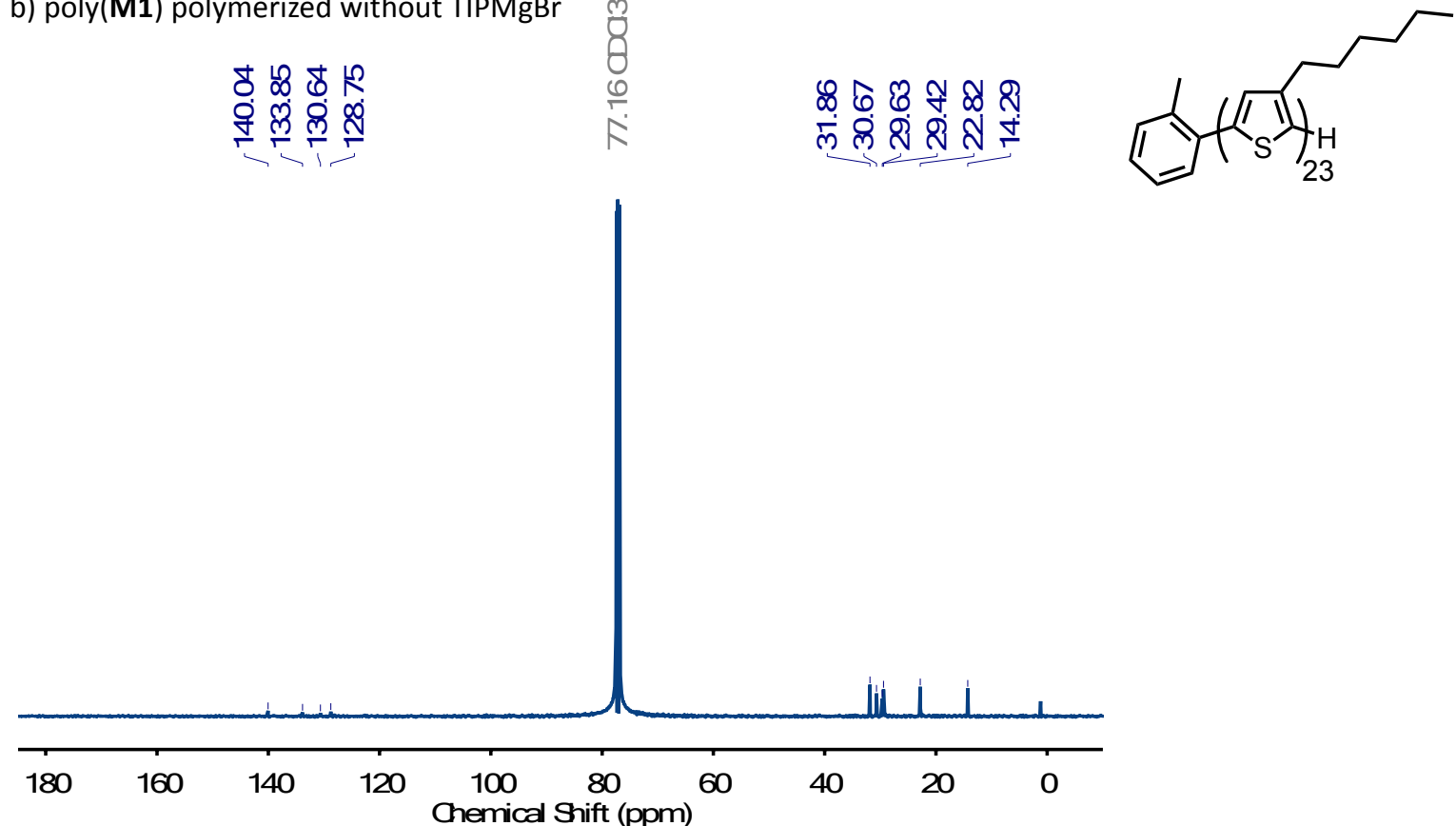

Figure S7: a) ${ }^{1} \mathrm{H}(500 \mathrm{MHz})$ and b) ${ }^{13} \mathrm{C}$ NMR $(126 \mathrm{MHz})$ of poly(M1) polymerized without $\mathrm{TIPMgBr}$, in $\mathrm{CDCl}_{3}$. From the integration ratio between the thiophene backbone protons and the $o$-tolyl methyl protons, the degree of polymerization is determined to be 23 repeat units. 
a) poly(M1) polymerized with 1 eq. TIPMgBr

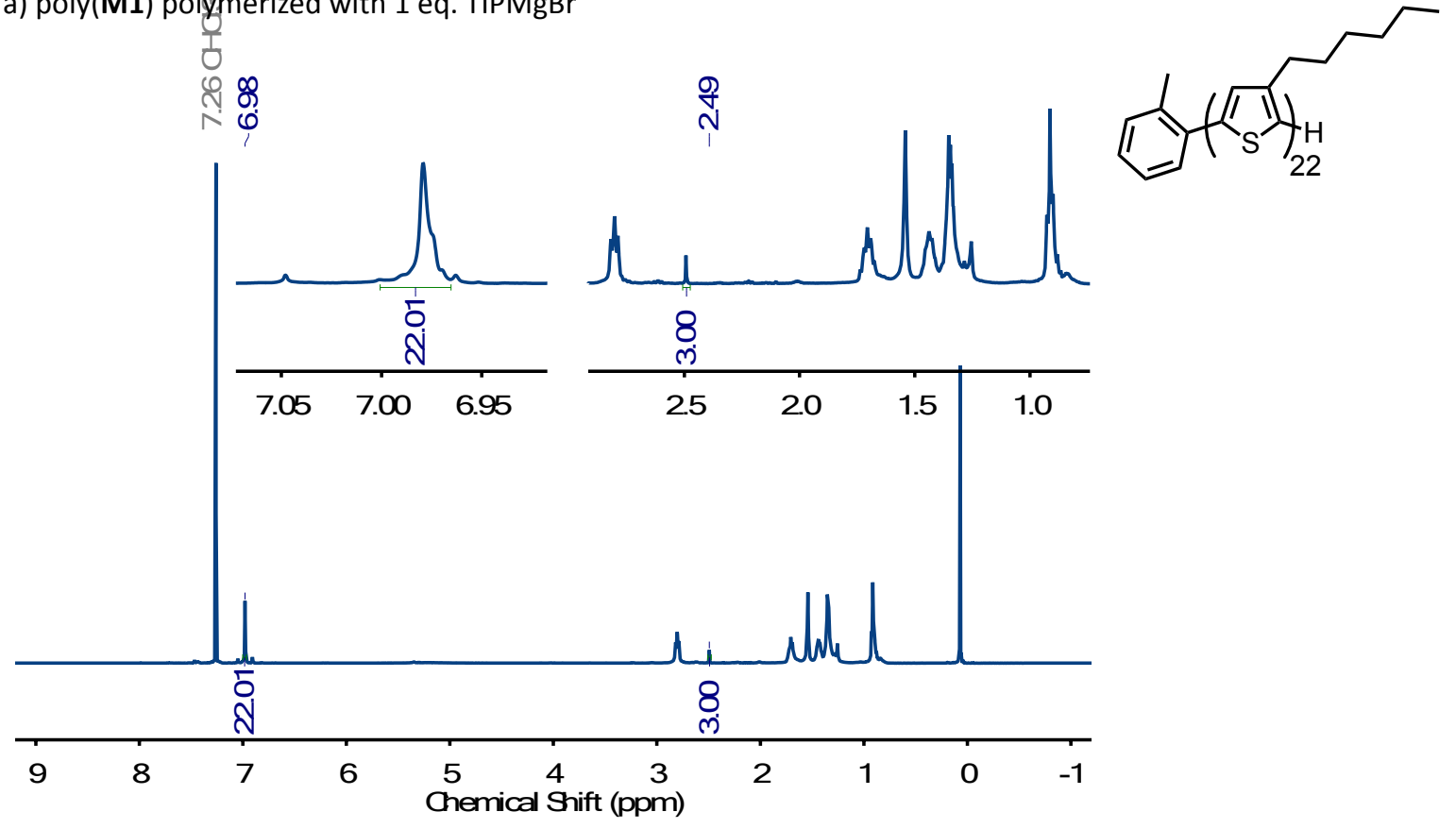

b) poly(M1) polymerized with 1 eq. TIPMgBr
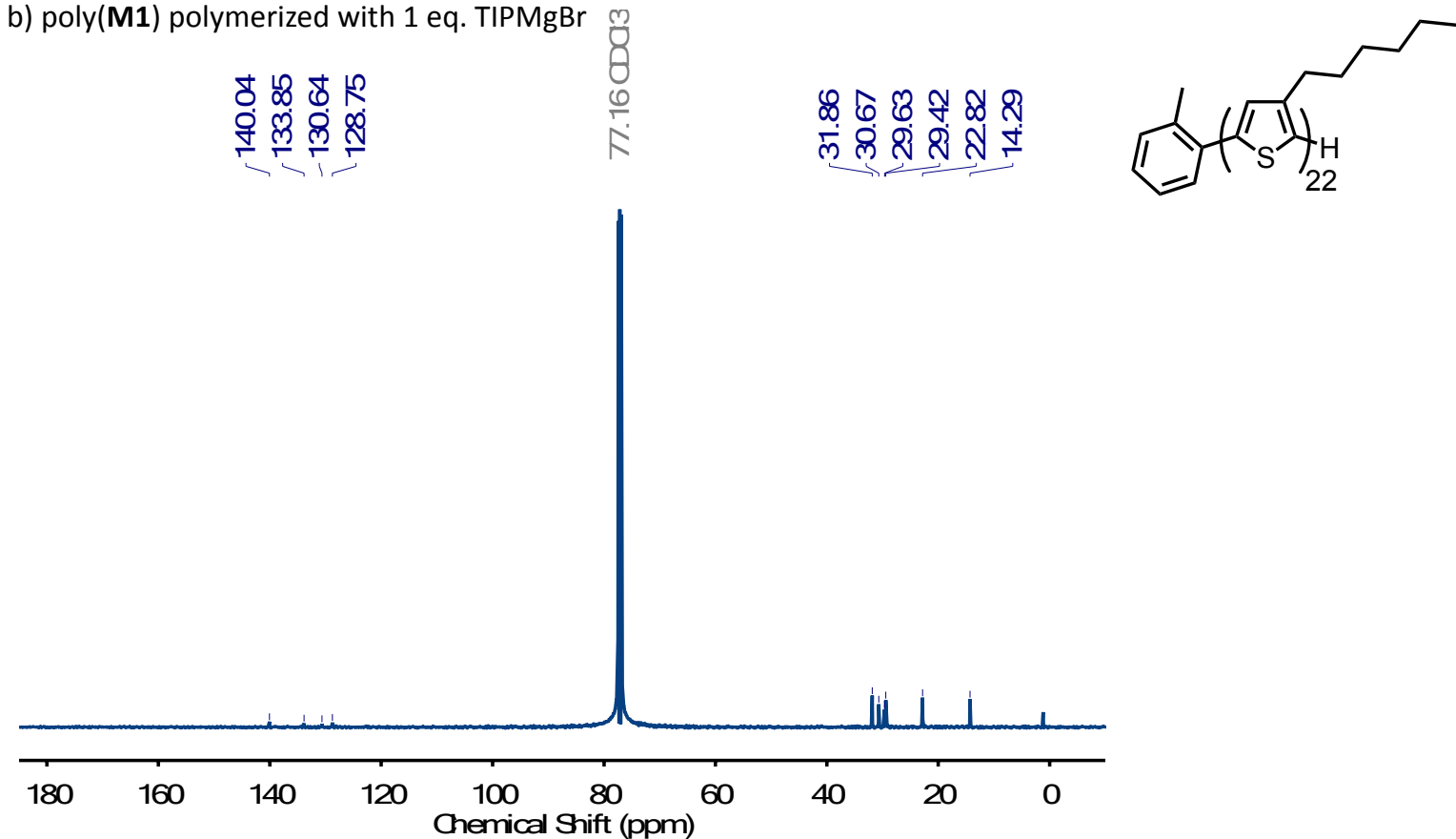

Figure S8: a) ${ }^{1} \mathrm{H}(500 \mathrm{MHz})$ and b) ${ }^{13} \mathrm{C}$ NMR $(126 \mathrm{MHz})$ of poly(M1) polymerized with 1 eq. $\mathrm{TIPMgBr}$, in $\mathrm{CDCl}_{3}$. From the integration ratio between the thiophene backbone protons and the $o$-tolyl methyl protons, the degree of polymerization is determined to be 22 repeat units. 


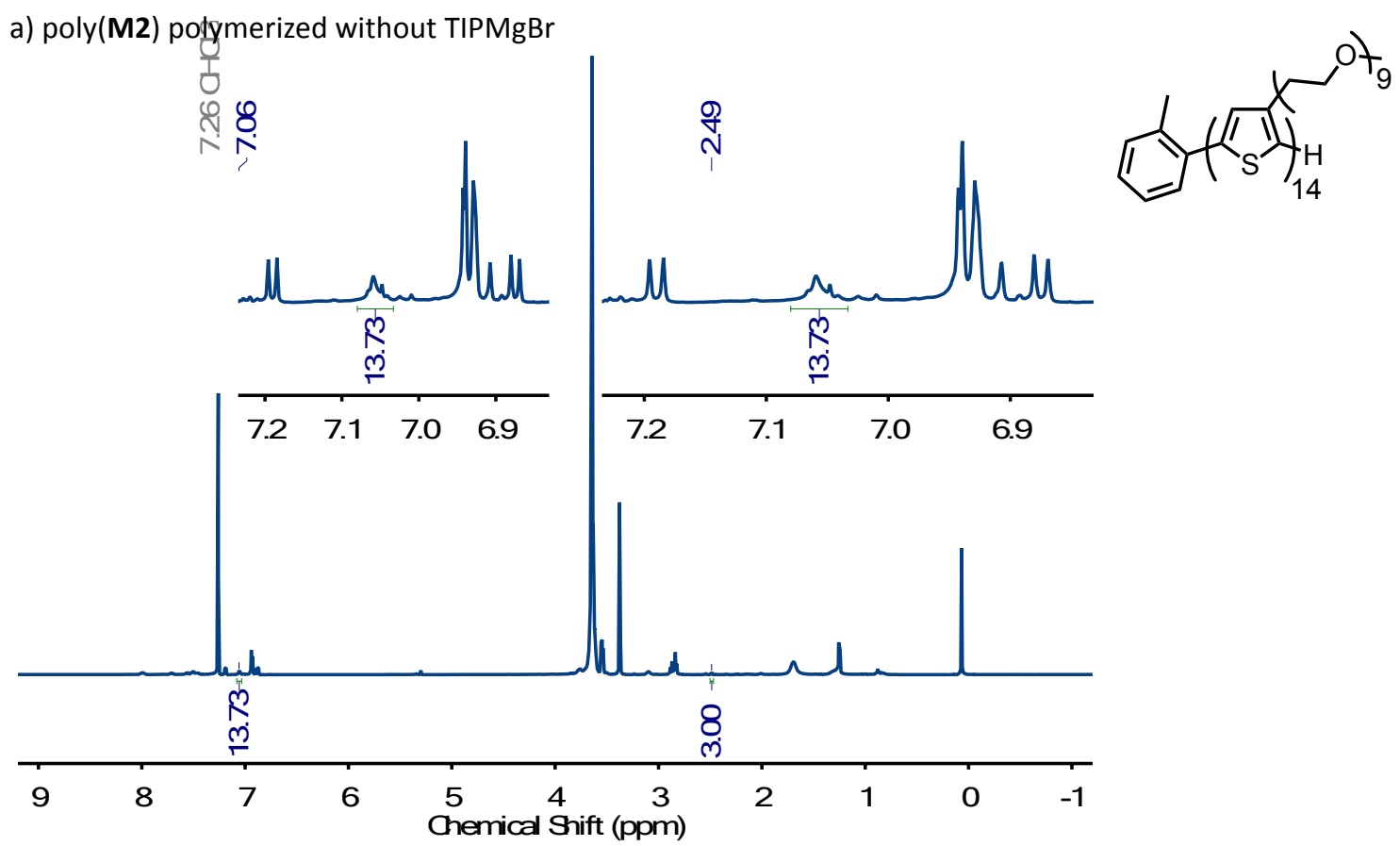

b) poly(M2) polymerized without $\mathrm{TIPMgBr}$

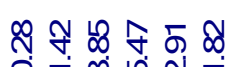

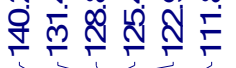
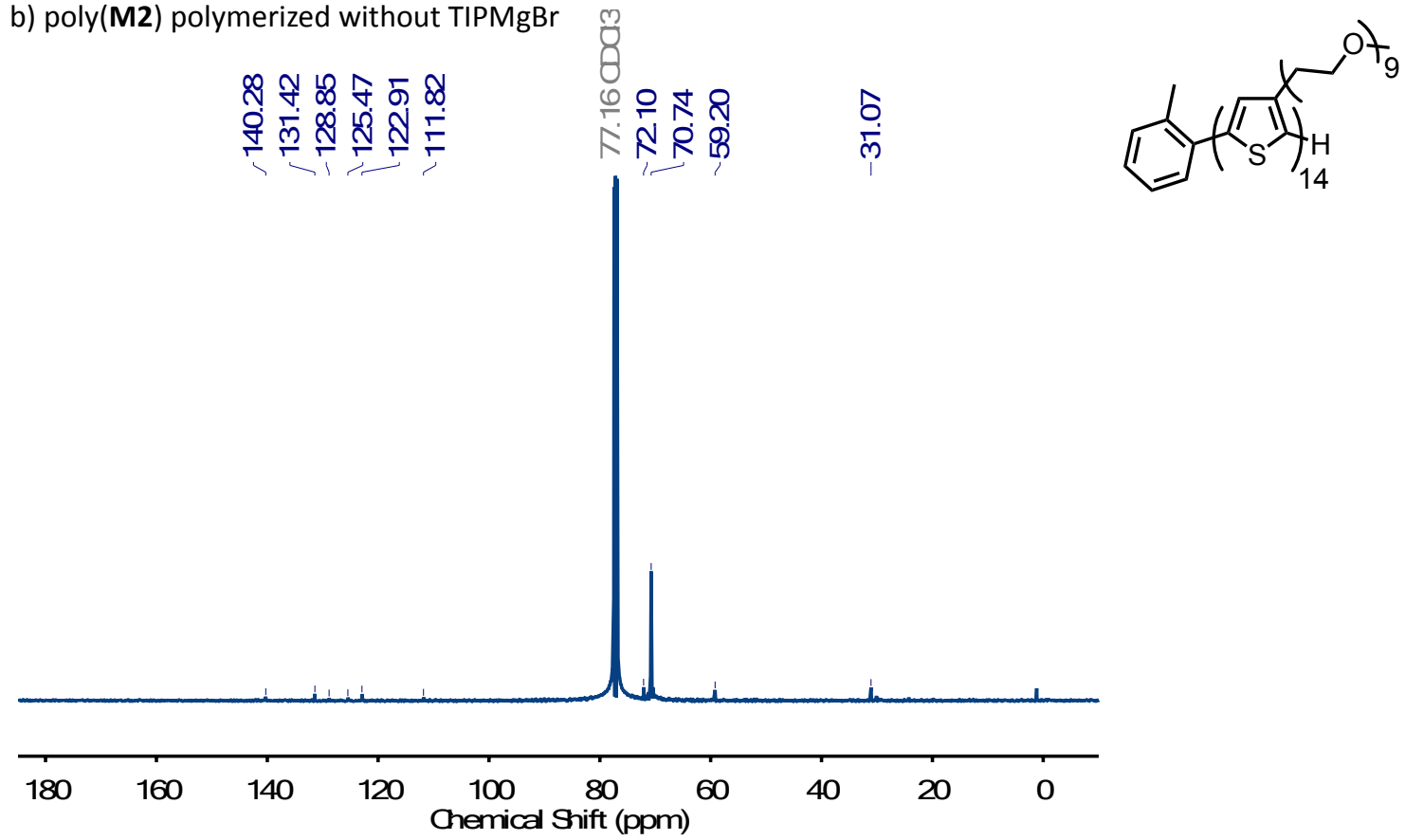

Figure S9: a) ${ }^{1} \mathrm{H}(500 \mathrm{MHz})$ and b) ${ }^{13} \mathrm{C}$ NMR $(126 \mathrm{MHz})$ of poly(M2) polymerized without $\mathrm{TIPMgBr}$, in $\mathrm{CDCl}_{3}$. From the integration ratio between the thiophene backbone protons and the $o$-tolyl methyl protons, the degree of polymerization is determined to be 14 repeat units. 


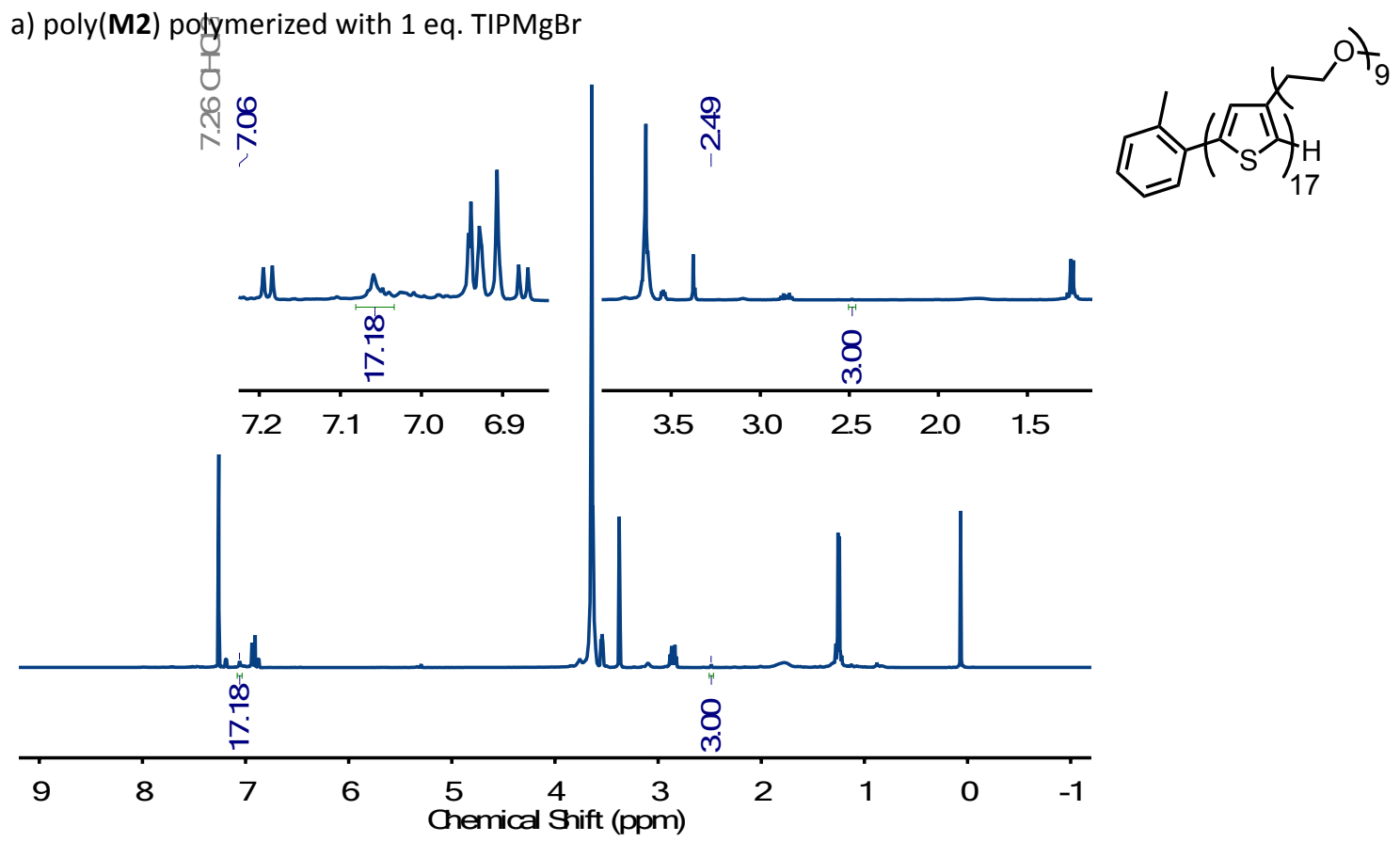

b) poly(M2) polymerized with 1 eq. $\mathrm{TIPMgBr}$

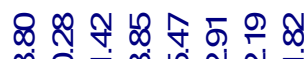

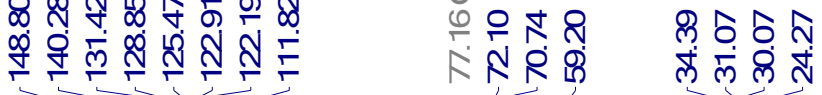
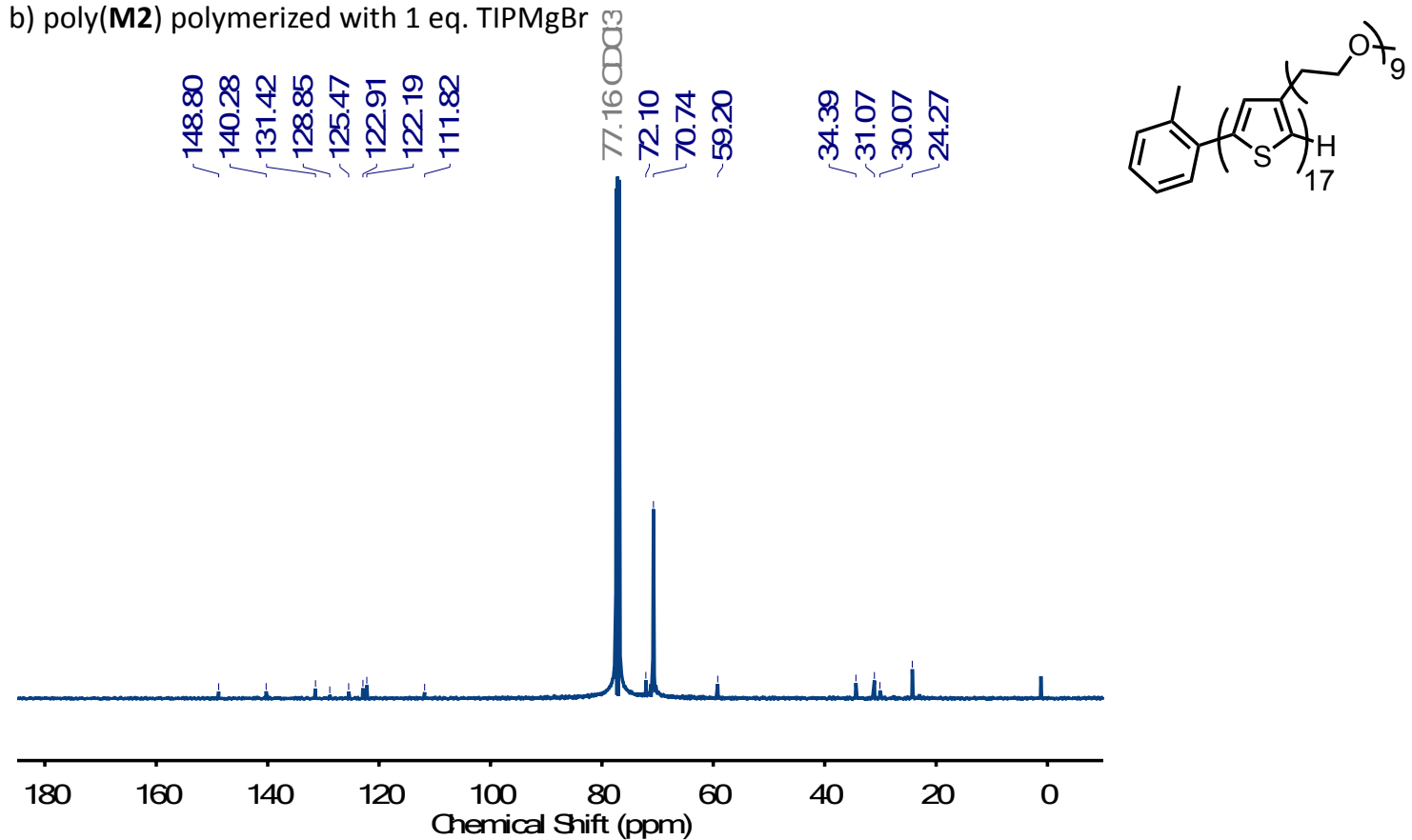

Figure S10: a) ${ }^{1} \mathrm{H}(500 \mathrm{MHz})$ and b) ${ }^{13} \mathrm{C} \mathrm{NMR}(126 \mathrm{MHz})$ of poly(M2) polymerized with 1 eq. $\mathrm{TIPMgBr}$, in $\mathrm{CDCl}_{3}$. From the integration ratio between the thiophene backbone protons and the $o$-tolyl methyl protons, the degree of polymerization is determined to be 17 repeat units. 


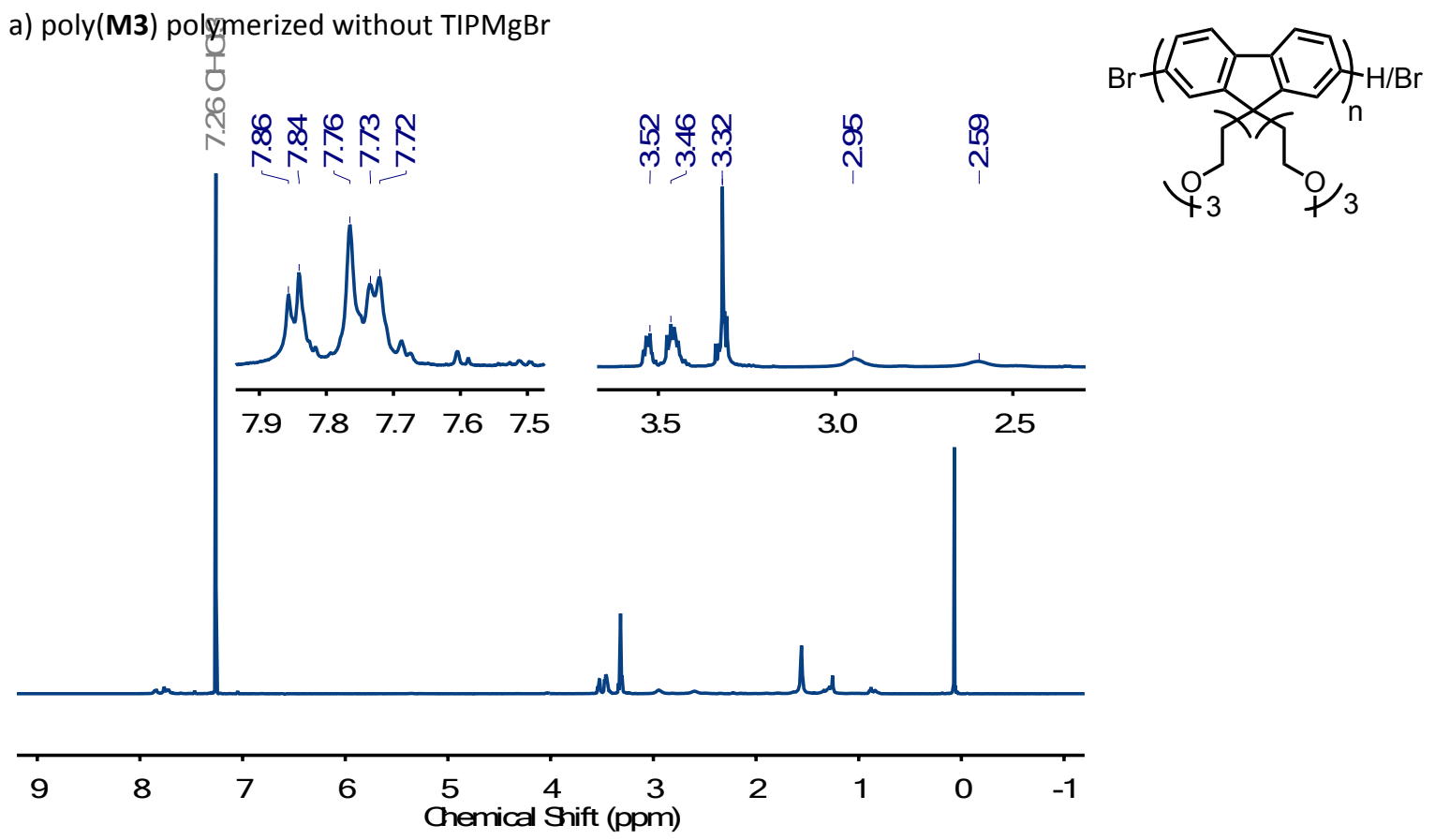

b) poly(M3) polymerized without TIPMgBr

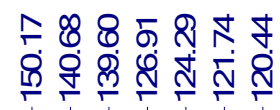

$88 \stackrel{5}{\circ}$

ㅅํำ

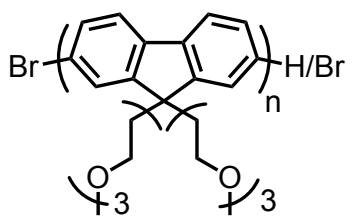

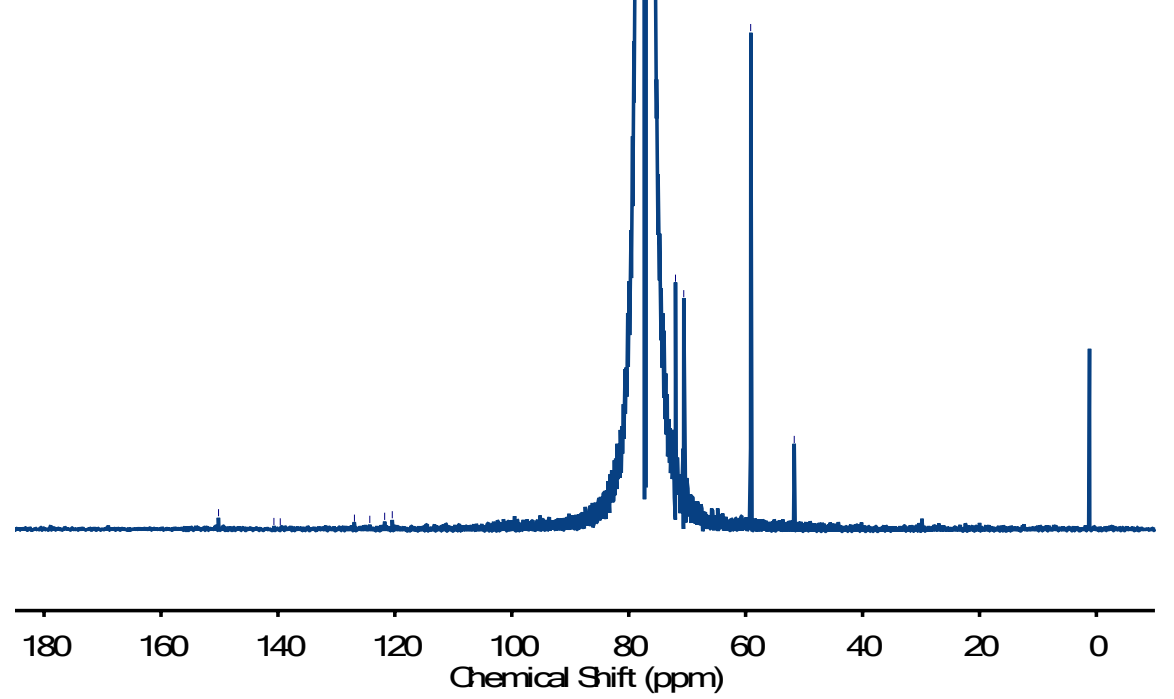

Figure S11: a) ${ }^{1} \mathrm{H}(500 \mathrm{MHz})$ and b) ${ }^{13} \mathrm{C}$ NMR $(126 \mathrm{MHz})$ of poly(M3) polymerized without TIPMgBr, in $\mathrm{CDCl}_{3}$ (Table S2, Entry 2). 

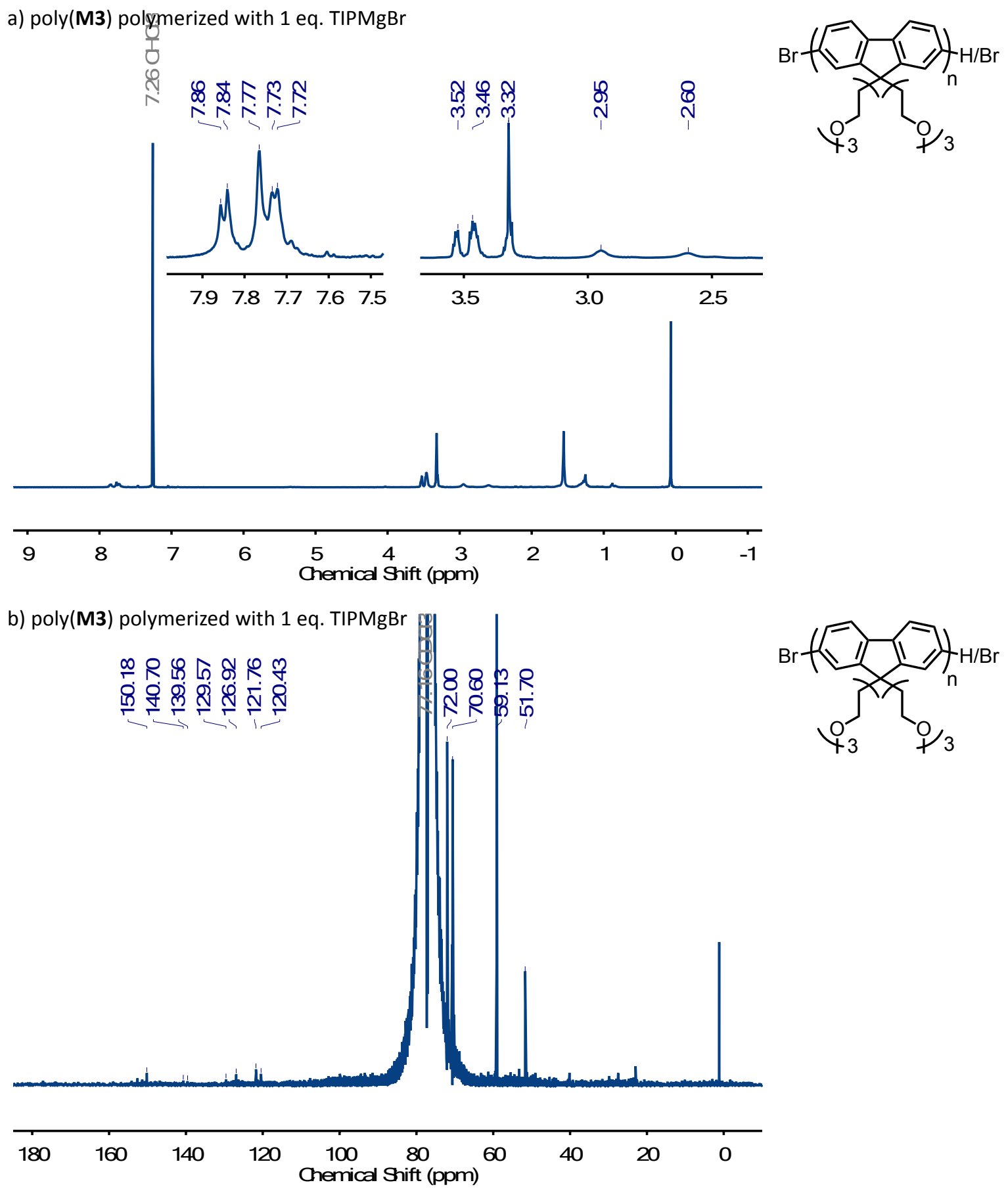

Figure S12: a) ${ }^{1} \mathrm{H}(500 \mathrm{MHz})$ and b) ${ }^{13} \mathrm{C}$ NMR (126 MHz) of poly(M3) polymerized with 1 eq. TIPMgBr, in $\mathrm{CDCl}_{3}$ (Table S2, Entry 1). 


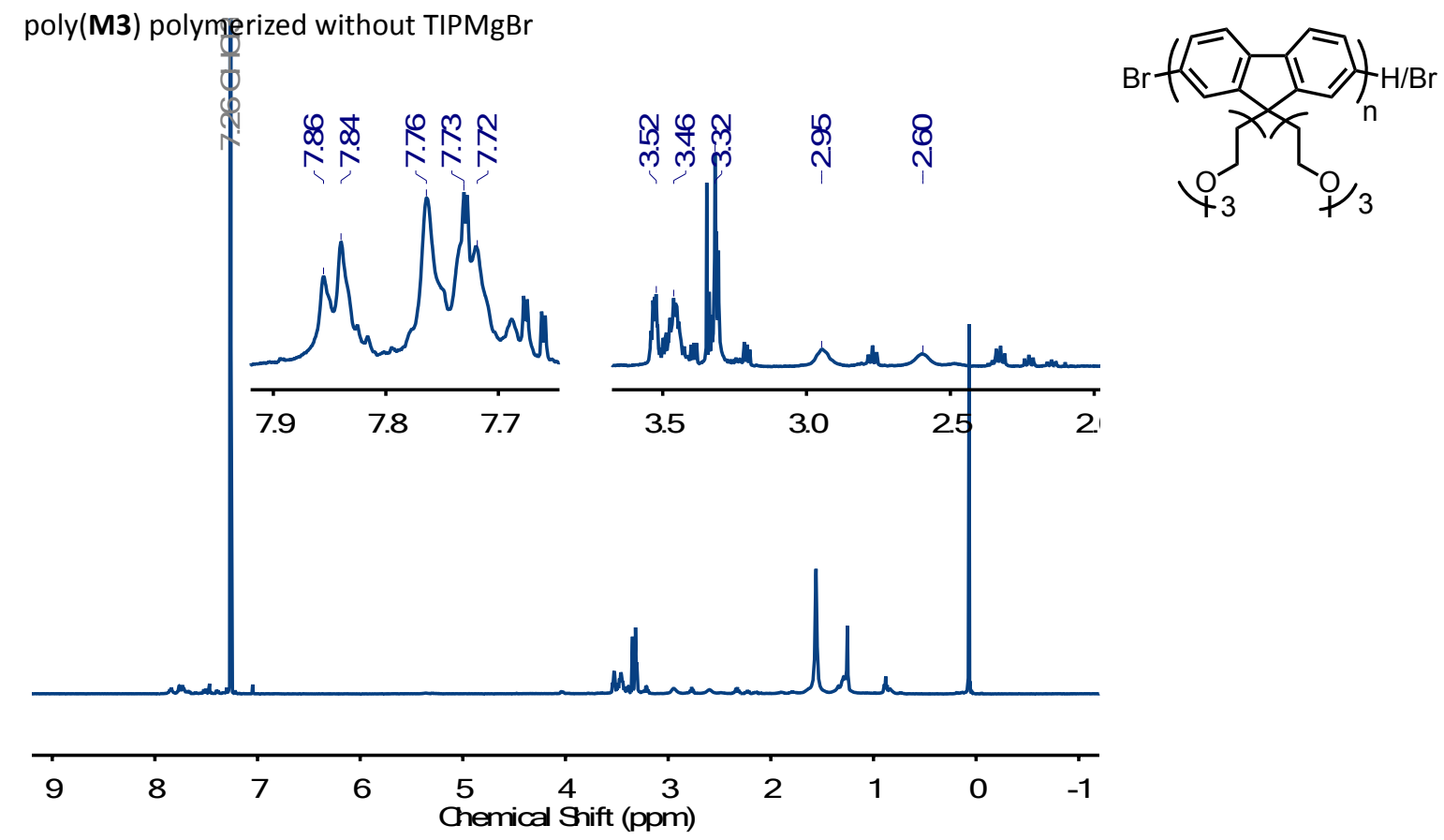

Figure S13: a) ${ }^{1} \mathrm{H}(500 \mathrm{MHz})$ of poly(M3) polymerized without $\mathrm{TIPMgBr}$, in $\mathrm{CDCl}_{3}(\mathrm{Table}$ S2, Entry 6).

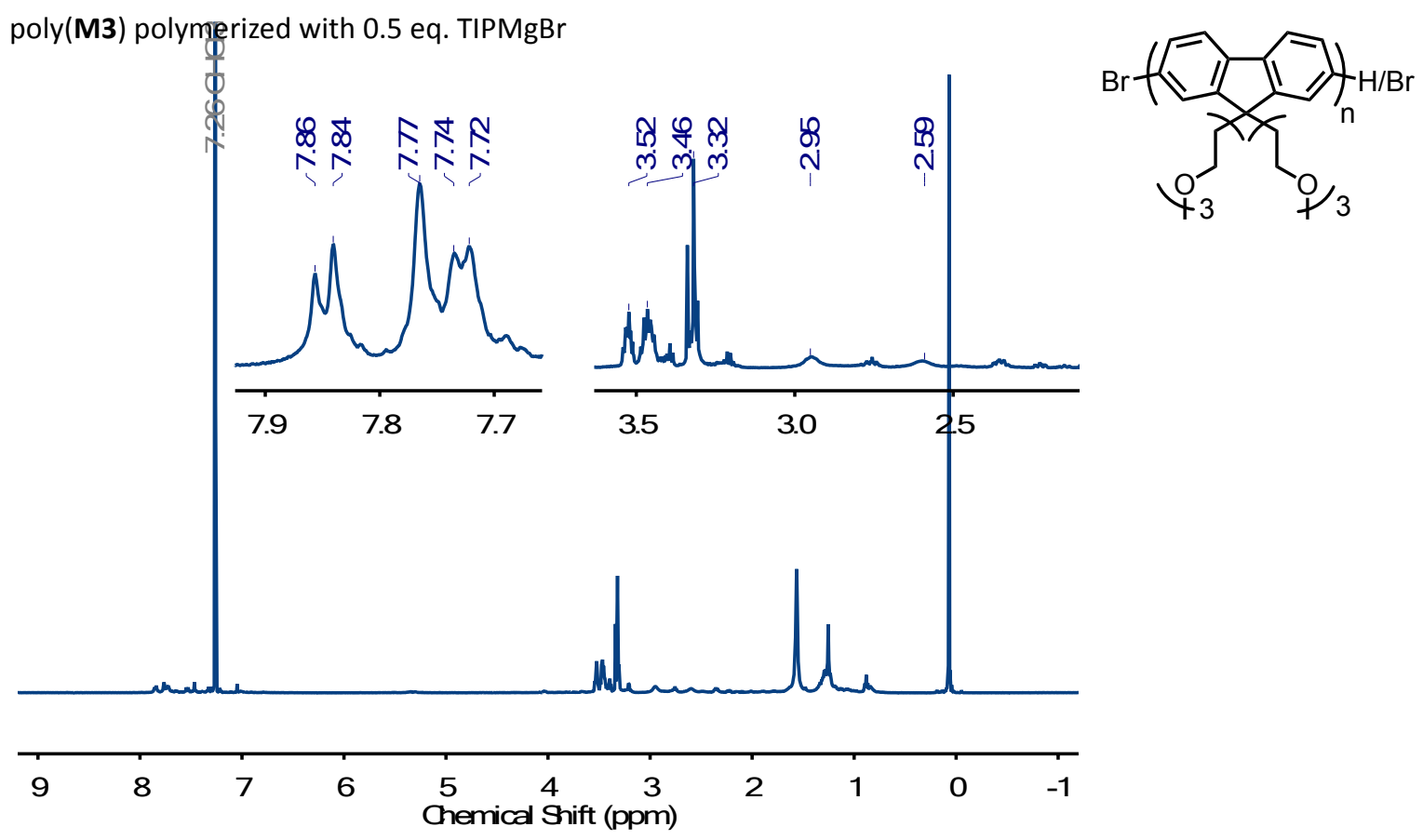

Figure S14: a) ${ }^{1} \mathrm{H}(500 \mathrm{MHz})$ of poly(M3) polymerized with 0.5 eq. TIPMgBr, in $\mathrm{CDCl}_{3}(\mathrm{Table}$ S2, Entry 5). 


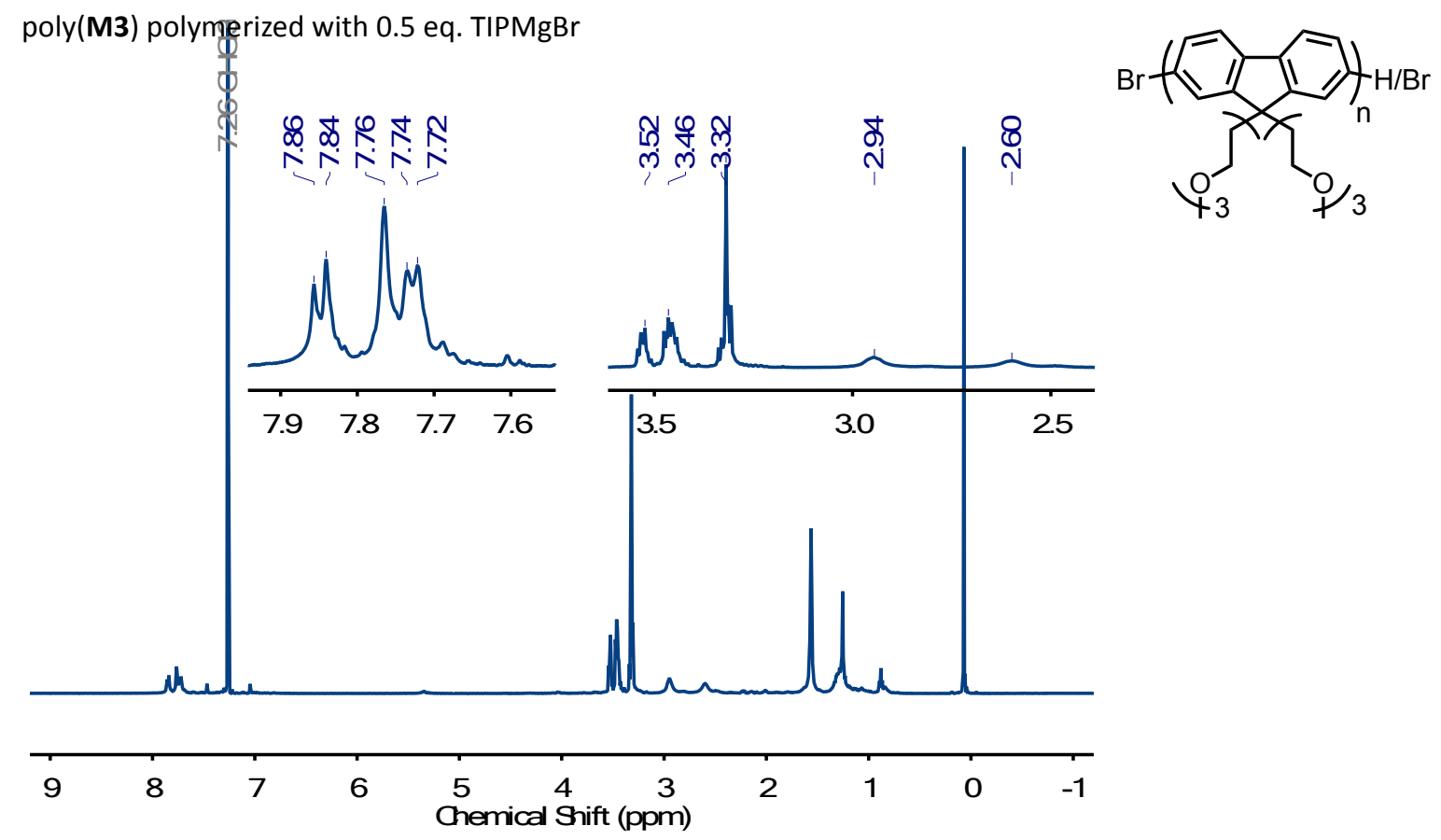

Figure S15: ${ }^{1} \mathrm{H}(500 \mathrm{MHz})$ of poly(M3) polymerized with 0.5 eq. $\mathrm{TIPMgBr}$, in $\mathrm{CDCl}_{3}(\mathrm{Table} \mathrm{S} 2$, Entry 3). 


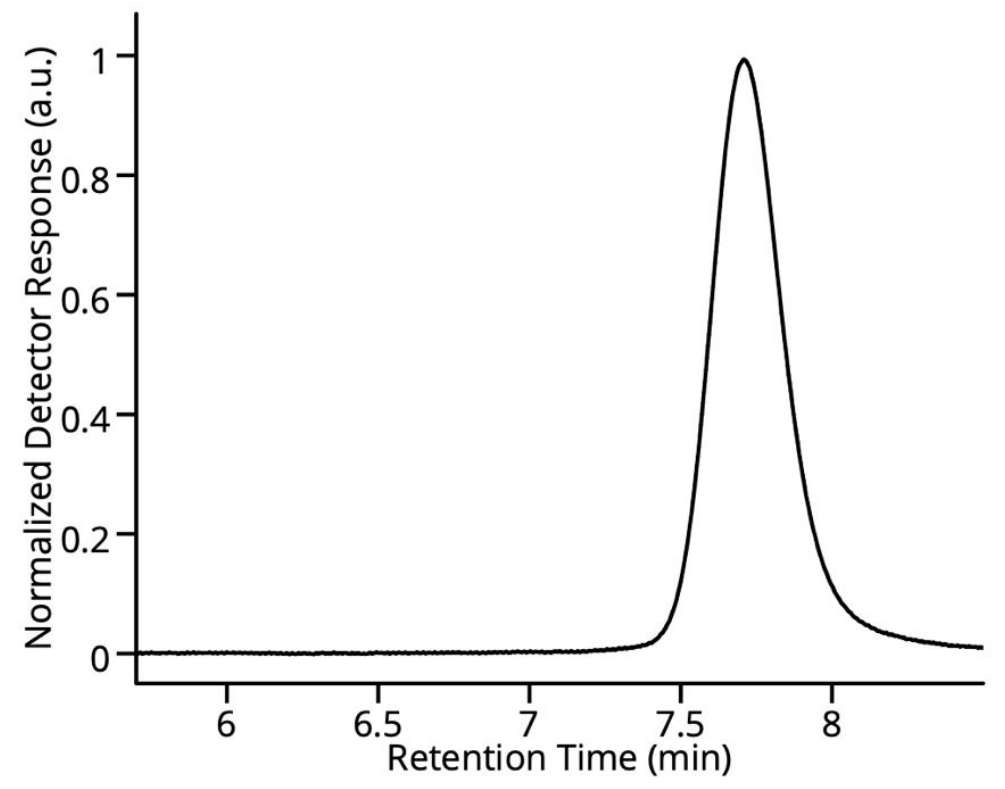

Figure S16: GPC trace of poly(M1) polymerized without $\mathrm{TIPMgBr}$ (eluent: $\mathrm{THF}, 40{ }^{\circ} \mathrm{C}$ ).

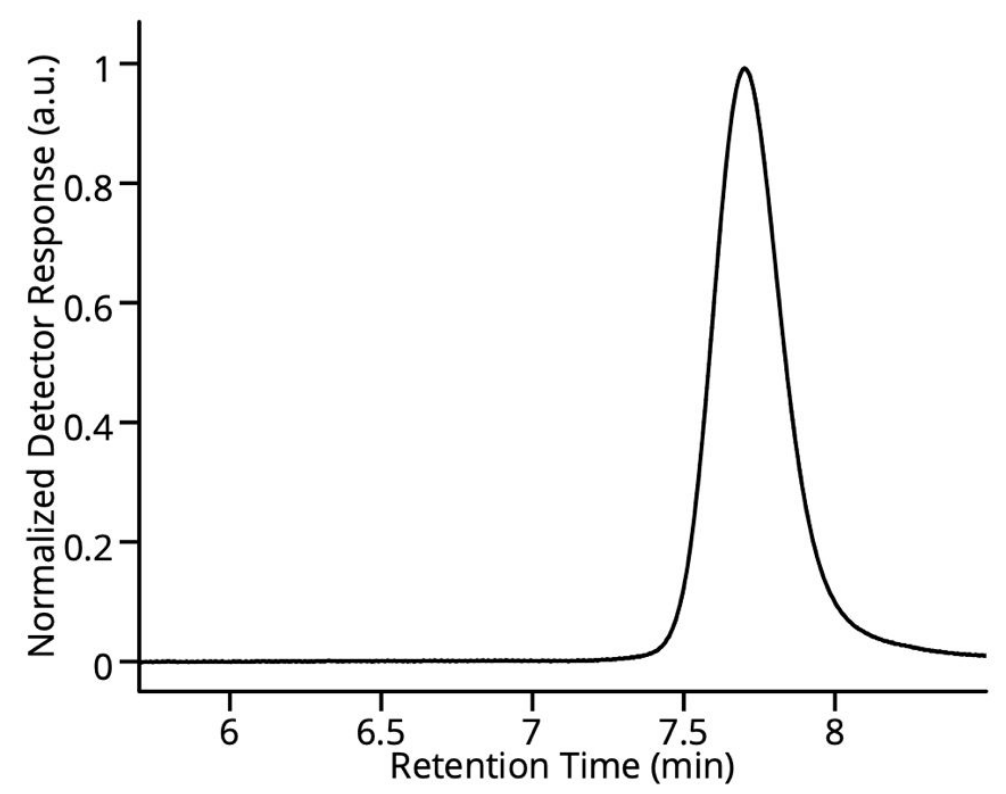

Figure S17: GPC trace of poly(M1) polymerized in the presence of 1 equivalent $\mathrm{TIPMgBr}$ (eluent: $\mathrm{THF}, 40^{\circ} \mathrm{C}$ ). 


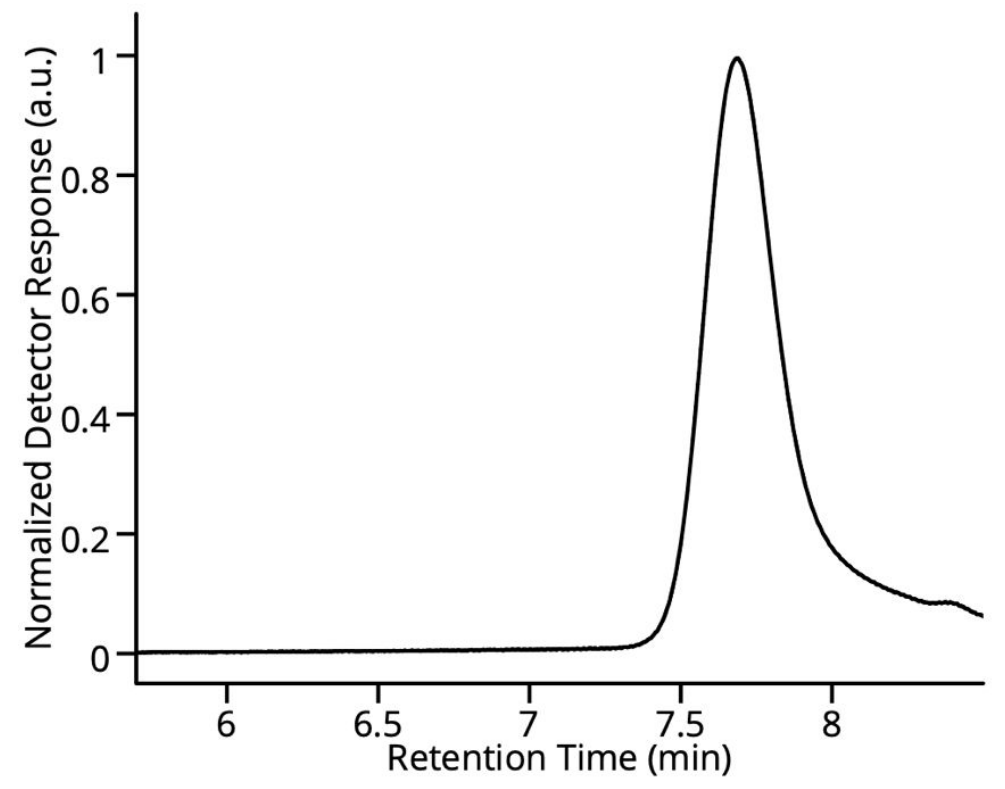

Figure S18: GPC trace of poly(M2) polymerized without $\mathrm{TIPMgBr}$ (eluent: $\mathrm{THF}, 40{ }^{\circ} \mathrm{C}$ ).

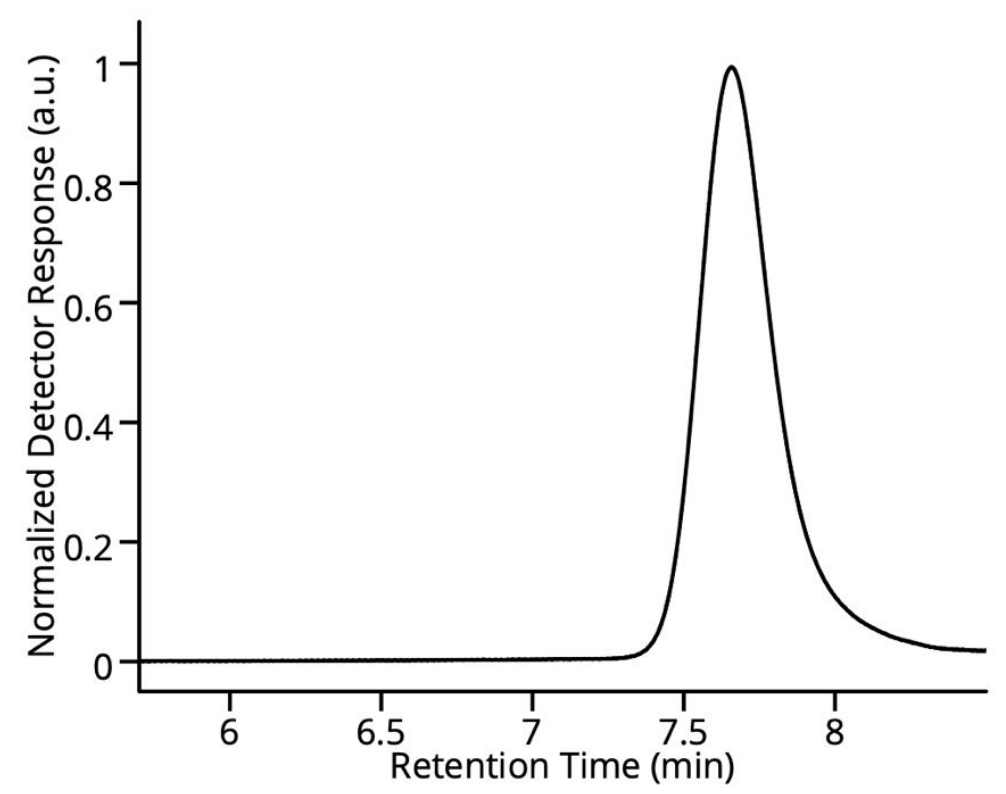

Figure S19: GPC trace of poly(M2) polymerized in the presence of 1 equivalent $\mathrm{TIPMgBr}$ (eluent: $\mathrm{THF}, 40^{\circ} \mathrm{C}$ ). 


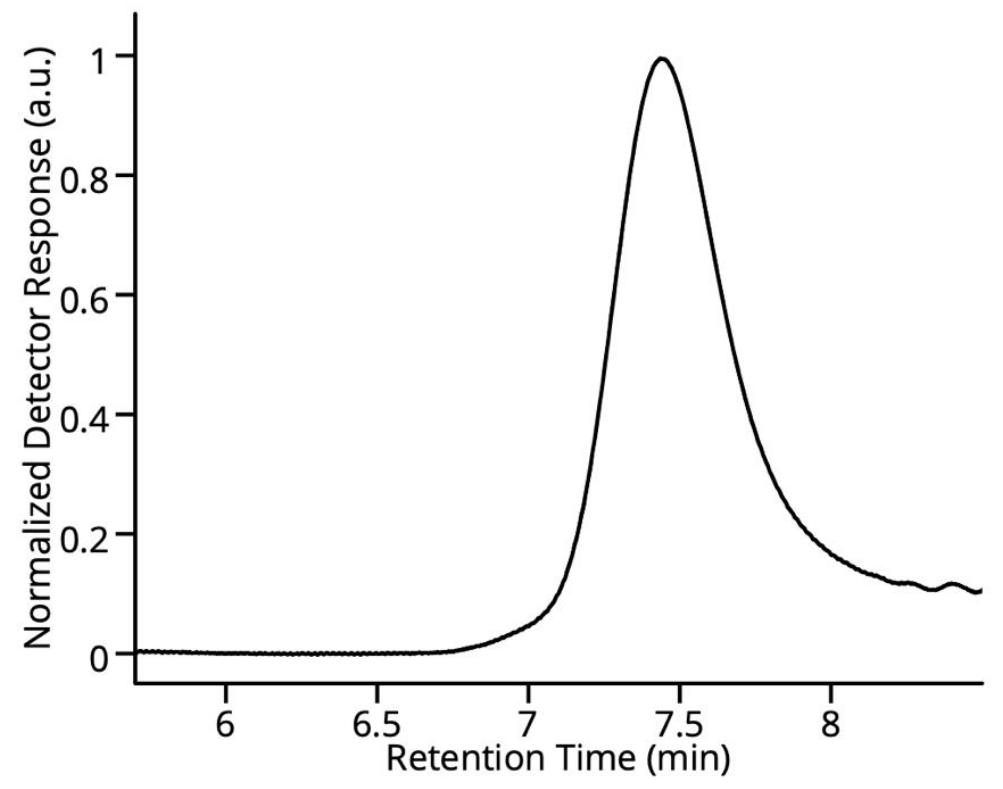

Figure S20: GPC trace of poly(M3) polymerized in the presence of 1 equivalent $\mathrm{TIPMgBr}$ (eluent: THF, $40{ }^{\circ} \mathrm{C}$ ).

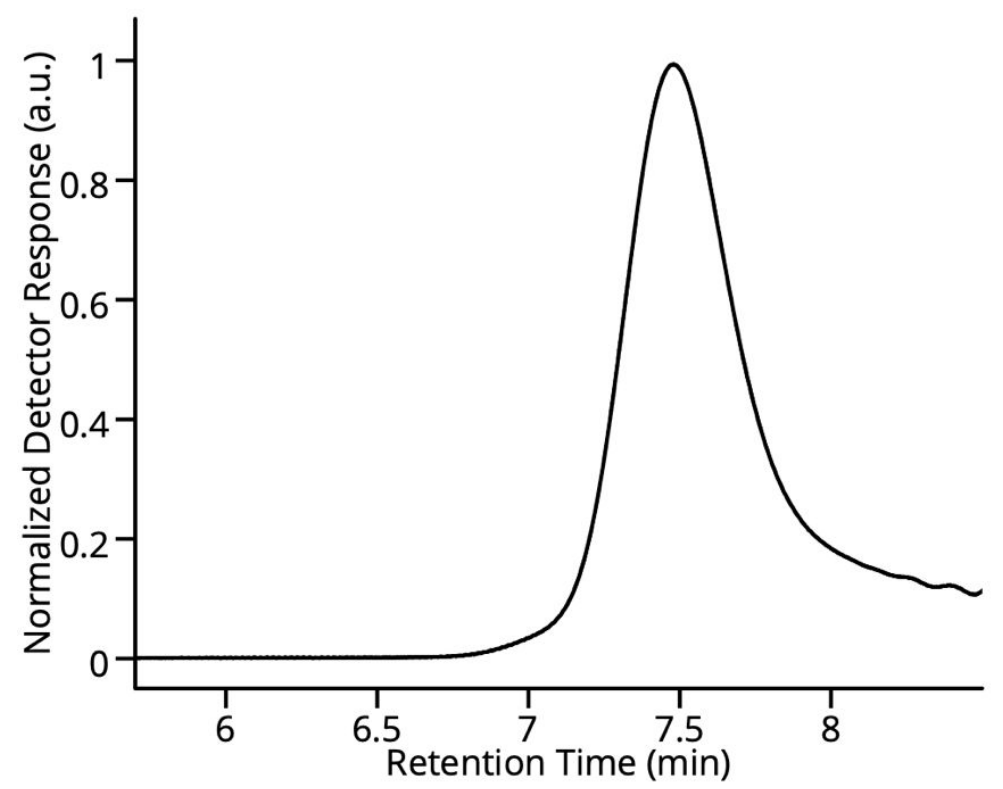

Figure S21: GPC trace of poly(M3) polymerized without TIPMgBr (eluent: $\mathrm{THF}, 40{ }^{\circ} \mathrm{C}$ ). 
Table S1: Summary of polythiophenes synthesized.

\begin{tabular}{ccccccccccc}
\hline Entry & Monomer & $\begin{array}{c}\text { Target } M_{\mathrm{n}} \\
(\mathrm{g} / \mathrm{mol})^{a}\end{array}$ & $\begin{array}{c}\text { Target } \\
\mathrm{DP}^{a}\end{array}$ & $\begin{array}{c}\mathrm{GPC} M_{\mathrm{n}} \\
(\mathrm{g} / \mathrm{mol})\end{array}$ & $\oplus$ & $\begin{array}{c}\text { NMR } M_{\mathrm{n}} \\
(\mathrm{g} / \mathrm{mol})^{b}\end{array}$ & $\begin{array}{c}\text { NMR } \\
\mathrm{DP}\end{array}$ & $\begin{array}{c}\text { Equiv. } \\
\text { TIPMgBr }\end{array}$ & $\begin{array}{c}\text { Isolated } \\
\text { Yield }(\%)\end{array}$ & $\begin{array}{c}\text { THF } \\
\text { Purification }\end{array}$ \\
\hline 1 & M1 & 5600 & 33 & 6300 & 1.07 & 3900 & 23 & 0 & 78 & SPS $^{c}$ \\
2 & M1 & 5600 & 33 & 6300 & 1.08 & 3700 & 22 & 1 & 81 & SPS \\
3 & M2 & 16400 & 33 & 5700 & 1.09 & 7000 & 14 & 0 & $-^{d}$ & SPS \\
4 & M2 & 16400 & 33 & 6100 & 1.08 & 8500 & 17 & 1 & $-d$ & SPS \\
\hline
\end{tabular}

${ }^{a}$ Based on $3 \%$ catalyst loading. The target $M_{\mathrm{n}}$ is calculated by the target degree of polymerization (DP) multiplied by the repeat unit mass, plus the two end group masses (o-tolyl and H). ${ }^{b}$ The NMR $M_{\mathrm{n}}$ is calculated by the NMR DP multiplied by the repeat unit mass, plus the two end group masses. ${ }^{c}$ Solvent purification system. ${ }^{2}$ An accurate yield could not be determined as we were unable to separate unreacted monomer from the polymer without extensive purification (eg. spin filtration or dialysis). This is a common challenge when working with PEGylated polymers, especially those containing longer PEG side chains, due to the similar and high solubilities of both the monomer and polymer product.

Table S2: Summary of polyfluorenes synthesized.

\begin{tabular}{ccccccccccc}
\hline Entry & Monomer & $\begin{array}{c}\text { Target } M_{\mathrm{n}} \\
(\mathrm{g} / \mathrm{mol})^{a}\end{array}$ & $\begin{array}{c}\text { Target } \\
\mathrm{DP}^{a}\end{array}$ & $\begin{array}{c}\mathrm{GPC} M_{\mathrm{n}} \\
(\mathrm{g} / \mathrm{mol})^{b}\end{array}$ & $\Xi^{b}$ & $\begin{array}{c}\mathrm{GPC} M_{\mathrm{n}} \\
(\mathrm{g} / \mathrm{mol})^{c}\end{array}$ & $\Xi^{c}$ & $\begin{array}{c}\text { Equiv. } \\
\text { TIPMgBr }\end{array}$ & $\begin{array}{c}\text { Isolated } \\
\text { Yield (\%) }\end{array}$ & $\begin{array}{c}\text { THF } \\
\text { Purification }\end{array}$ \\
\hline 1 & M3 & 9200 & 20 & 8400 & 1.31 & $n / a$ & $n / a$ & 1 & 40 & SPS $^{d}$ \\
2 & M3 & 9200 & 20 & 7200 & 1.39 & $n / a$ & $n / a$ & 0 & 40 & SPS \\
3 & M3 & 9200 & 20 & 9800 & 1.13 & 12100 & 1.16 & 0.5 & 28 & deoxygenated \\
4 & M3 & 9200 & 20 & $-e$ & $-e$ & $-^{e}$ & $-e$ & 0 & 0 & deoxygenated \\
5 & M3 & 9200 & 20 & 9700 & 1.09 & 12600 & 1.16 & 0.5 & $-f$ & distilled \\
6 & M3 & 9200 & 20 & 6700 & 1.20 & 8000 & 1.24 & 0 & $-f$ & distilled \\
\hline
\end{tabular}

${ }^{a}$ Based on $5 \%$ catalyst loading. The target $M_{\mathrm{n}}$ is calculated by the target degree of polymerization (DP) multiplied by the repeat unit mass, plus the two end group masses (o-tolyl and H). ${ }^{b}$ THF GPC, relative to polystyrene calibration standards. ${ }^{c} \mathrm{THF}$ GPC, relative to PMMA calibration standards. ${ }^{d}$ Solvent purification system. ${ }^{2}$ No polymer formed. ${ }^{f}$ An accurate yield could not be determined as we were unable to separate unreacted monomer from the polymer without extensive purification (eg. spin filtration or dialysis). 
Calculation of expected DP based on polymerizable activated monomer ratio

$\mathrm{DP}_{\text {Target }}=($ moles monomer $) /($ moles catalyst $)=33$

$\mathrm{DP}_{\text {Expected, } \mathbf{M} 1}=0.80 * \mathrm{DP}_{\text {Target }}=26$

This is the DP we would expect if we account for the fact that only $80 \%$ of activated monomers are the polymerizable isomer for M1

$\mathrm{DP}_{\text {Expected, } \mathbf{M} 2}=0.60 * \mathrm{DP}_{\text {Target }}=20$

This is the DP we would expect if we account for the fact that only $60 \%$ of activated monomers are the polymerizable isomer for $\mathbf{M} 2$

References:

(1) McKeown, G. R.; Ye, S.; Cheng, S.; Seferos, D. S. Homogenous Synthesis of Monodisperse High Oligomers of 3-Hexylthiophene by Temperature Cycling. J. Am. Chem. Soc. 2019, 141 (43), 17053-17056.

(2) Pangborn, A. B.; Giardello, M. A.; Grubbs, R. H.; Rosen, R. K.; Timmers, F. J. Safe and Convenient Procedure for Solvent Purification. Organometallics 1996, 15 (5), 1518-1520. 